\title{
Capture of Acidic Gases from Flue Gas by Deep Eutectic Solvents
}

\author{
Yan Wang ${ }^{1}\left(\mathbb{D}\right.$, Shuhang Ren ${ }^{1, *}$, Yucui Hou ${ }^{2}$ and Weize $\mathrm{Wu}^{1, *(\mathbb{D})}$ \\ 1 State Key Laboratory of Chemical Resource Engineering, Beijing University of Chemical Technology, \\ Beijing 100029, China; 2020400041@mail.buct.edu.cn \\ 2 Department of Chemistry, Taiyuan Normal University, Jinzhong 030619, China; houyc@tynu.edu.cn \\ * Correspondence: rensh@mail.buct.edu.cn (S.R.); wzwu@mail.buct.edu.cn (W.W.)
}

check for

updates

Citation: Wang, Y.; Ren, S.; Hou, Y.; $\mathrm{Wu}, \mathrm{W}$. Capture of Acidic Gases from Flue Gas by Deep Eutectic Solvents. Processes 2021, 9, 1268. https:// doi.org/10.3390/pr9081268

Academic Editor: Mert Atilhan

Received: 31 May 2021

Accepted: 13 July 2021

Published: 22 July 2021

Publisher's Note: MDPI stays neutral with regard to jurisdictional claims in published maps and institutional affiliations.

Copyright: (c) 2021 by the authors. Licensee MDPI, Basel, Switzerland. This article is an open access article distributed under the terms and conditions of the Creative Commons Attribution (CC BY) license (https:/ / creativecommons.org/licenses/by/ $4.0 /)$.

\begin{abstract}
Up to now, many kinds of deep eutectic solvents (DESs) were investigated for the capture of acidic gases from flue gases. In this review, non-functionalized and functionalized DESs, including binary and ternary DESs, for $\mathrm{SO}_{2}, \mathrm{CO}_{2}$ and $\mathrm{NO}$ capture, are summarized based on the mechanism of absorption, physical interaction or chemical reaction. New strategies for improving the absorption capacity are introduced in this review. For example, a third component can be introduced to form a ternary DES to suppress the increase in viscosity and improve the $\mathrm{CO}_{2}$ absorption capacity. DESs, synthesized with halogen salt hydrogen bond acceptors (HBAs) and functionalized hydrogen bond donors (HBDs), can be used for the absorption of $\mathrm{SO}_{2}$ and $\mathrm{NO}$ with high absorption capacities and low viscosities after absorption, due to physicochemical interaction between gases and DESs. Emphasis is given to introducing the absorption capacities of acidic gases in these DESs, the mechanism of the absorption, and the ways to enhance the absorption capacity.
\end{abstract}

Keywords: deep eutectic solvents; capture; sulfur dioxide; carbon dioxide; nitric oxide

\section{Introduction}

Acidic gases, such as sulfur dioxide $\left(\mathrm{SO}_{2}\right)$, nitric oxide $(\mathrm{NO})$ and carbon dioxide $\left(\mathrm{CO}_{2}\right)$, are the main pollutants of fuel gases, which are mainly released from the combustion of fossil fuels (coal, oil, and natural gas), posing a significant threat to the environment by forming acid rain, ozone destruction, global warming and so on. Due to the high hazards of these acidic gases, various methods have been developed to reduce their emissions, such as lime-limestone flue gas desulfurization process for $\mathrm{SO}_{2}$ capture [1], carbon dioxide capture and sequestration process for $\mathrm{CO}_{2}$ capture [2], selective catalytic reduction, and selective non-catalytic reduction for NO conversion [3,4]. Nevertheless, the drawbacks of them are obvious, such as volatility of absorbents, catalyst poisoning, substantial energy consumption and corrosiveness, the generation of huge amounts of byproduct and wastewater, which may generate secondary pollution to the environment if not properly treated. Therefore, it is necessary to capture the acidic gases with high efficiency, low cost, no by-products and high sustainability. Some work has been focused on the solutions to the above problems, among them one of the most effective and feasible ways is to develop novel recyclable green absorbents with high absorption efficiency and low desorption energy consumption.

Over the past two decades, ionic liquids (ILs) have received the most extensive attention in the field of gas absorption, owing to their unique characteristics. The promising advantages of ILs that can be used for gas capture are their negligible vapor pressures and their design ability by changing the structures of their cations and anions to meet different needs. The lower vapor pressure cannot only ensure no contamination of the gas stream but also lower the energy consumption and solvent regeneration. Hence, considerable efforts have been made to design novel ILs able to solubilize acidic gases physically and/or chemically [5-7]. For non-functionalized ILs that are able to dissolve acidic gases physically, 
the solubility of gases is proportional to its partial pressure, which has the advantage of absorbing high-pressure gases, and follows Henry's Law. For functionalized ILs, the gas solubility follows the chemical equilibrium and pressure is not significantly effective, so it can be used to absorb low-concentration gases. Although it is reported that ILs with halogen anions or halogen-containing anions can effectively absorb $\mathrm{SO}_{2}$ through charge transfer interactions, the analysis confirmed that it was a physical absorption [8-11]. The solubility of gases in ILs driven by a physical absorption at low partial pressures is too low to develop a practical separation process. To obtain a higher absorptive capacity, ILs with functionalized groups such as carboxylate, azolate, amine, and acylamido were developed for acidic gas chemisorption [12-17]. Generally, compared to the traditional solvents, ILs have made great improvement in gas absorption; however, the high cost, complicated synthesizing and high viscosity impede its development in gas absorption, which inspire people to seek novel and efficient solvents [18,19].

Deep eutectic solvents (DESs), as IL analogs, have been developed on the basis of IL research, which share many of the same general characteristics. In addition to low vapor pressure, relatively wider liquid range and equivalent absorption capacity, DESs also have the advantages of low cost, low viscosity, convenient synthesis and easy achievement of dual functions compared to ILs. Therefore, DESs are considered to be promising alternatives to ILs. DESs with high purity can be easily prepared by mixing hydrogen bond donors (HBDs) and hydrogen bond acceptors (HBAs), which may contain two or more constituents, and does not require further purification, therefore simplifying the processes. The interactions between the constituents can be hydrogen bonds, halogen bonds, or Pi-Pi interactions that cause the melting point of synthesized DES to be significantly reduced and lower than any of the individual component [20-22]. Abbott et al. [23] reported the first example of DES through mixing choline chloride (ChCl) with urea (UE), and then Zhu et al. [24] reported that $\mathrm{ChCl}$ :UE DES can effectively catalyze the reactions of $\mathrm{CO}_{2}$ and epoxides. After that a significant number of studies were conducted on the capacity of the multifarious DESs for acidic gases absorption.

Recently, several reviews focusing on DESs were published. For instance, Hansen et al. reviewed various applications, physicochemical properties, and characterization techniques applicable to DESs [25]. Ji et al. [26] reviewed IL/DES-based absorbents for $\mathrm{CO}_{2}$ capture, together with COSMO-RS models. Wu et al. [27] reviewed general trends in the development of DESs for the separation of mixtures. Chen et al. [28] gave a comprehensive summary of toxic gases capture by DESs, and reviewed the effects of HBD and HBA, temperature, their molar ratio, water content and gas flow rate on the absorption capacity. Generally, the factors that affect the gases capture capability of DESs can be divided into two categories: internal factors (e.g., structure of HBA and HBD, and molar ratio) and external factors (e.g., temperature, pressure, time, gas flow rate, and water content). To the best of our knowledge, almost all DESs follow the law that the absorption capacity decreases with the increase of temperature. The influence of water content $(<8 \%)$ on the absorption of DESs is uncertain but generally slight. Gas flow rate only influences absorption/desorption rate and the time to reach absorption equilibrium. The gas solubility is proportional to its partial pressure for non-functionalized DESs. The saturated capacity of functionalized DESs increases with the increase of gas partial pressure. Therefore, the influence of external factors on absorption capacity will not be discussed here. In this review, we mainly focus on the influence of the nature and molar ratio of HBAs/HBDs on gas capture capacity and desorption rate. The functionalized and non-functionalized DESs were reviewed, according to whether chemical reactions occurred to form new substances or not, for $\mathrm{SO}_{2}$, $\mathrm{CO}_{2}$ and $\mathrm{NO}$ capture, respectively. This perspective includes the following sections: (1) non-functionalized DESs for $\mathrm{SO}_{2}$ capture, (2) functionalized DESs for $\mathrm{SO}_{2}$ capture, (3) non-functionalized DESs for $\mathrm{CO}_{2}$ capture, (4) functionalized DESs for $\mathrm{CO}_{2}$ capture, (5) functionalized DESs for NO capture, (6) conclusions and outlooks. 


\section{Non-Functionalized DESs for $\mathrm{SO}_{2}$ Capture}

The $\mathrm{S}$ atom in $\mathrm{SO}_{2}$ is $\mathrm{sp} 2$ hybridized to form two $\sigma$ bonds with two $\mathrm{O}$ atoms, which is a V-shaped geometric structure. The uneven distribution of positive and negative charges between the sulfur atom and the two oxygen atoms resulting in a great net dipole, which means that its dipole-dipole interaction is very strong. According to the "law of similarity and intermiscibility" principle, $\mathrm{SO}_{2}$ can be easy absorbed by polar solvents through physical interaction. Thus, selecting polar organics as HBDs or HBAs is one way to improve the absorption capacity of DESs.

\subsection{Caprolactam-Based DESs}

In 2010, Duan et al. [29] synthesized a series of DESs by mixing caprolactam (CPL) and tetrabutyl ammonium bromide (TBAB) with different molar ratios. The solubility of $\mathrm{SO}_{2}$ in CPL:TBAB DES (1:1) is about $0.1 \mathrm{~g} \mathrm{SO}_{2} / \mathrm{g}$ DES at $298.2 \mathrm{~K}$ and $101 \mathrm{kPa}$. They found the solubility of $\mathrm{SO}_{2}$ decreased as both temperature and the molar ratio of CPL to TBAB increased, due to CPL is a weakly polar molecule. Then, Liu et al. [30] investigated a series of CPL-based DES with more polar organic acids and bases, such as acetamide (AA), furoic acid, benzoic acid, o-toluic acid. CPL: AA DES with a molar ratio of 1:1 presents the highest $\mathrm{SO}_{2}$ solubility of $0.497 \mathrm{~g} \mathrm{SO}_{2} / \mathrm{g}$ DES at $303.15 \mathrm{~K}$ and $101 \mathrm{kPa} .{ }^{1} \mathrm{H}$ NMR analysis confirmed that CPL: AA DES absorbed $\mathrm{SO}_{2}$ through physical interaction. The $\mathrm{SO}_{2}$ absorption capacity of CPL:AA DES is higher than that of CPL:organic acids DESs. After that, they developed an inorganic thiocyanate-based DESs paired with organic bases to improve the $\mathrm{SO}_{2}$ absorption capacity [31], based on the report that thiocynate and dicyanide anions in ILs play an important role in the physical capture of $\mathrm{SO}_{2}[32,33]$. CPL:KSCN DES (3:1) possessed $\mathrm{SO}_{2}$ solubility of $0.607 \mathrm{~g} \mathrm{SO}_{2} / \mathrm{g}$ DES at $293.15 \mathrm{~K}$ and 101 $\mathrm{kPa}$. The DESs could be easily regenerated under vacuum at $343.15 \mathrm{~K}$ and recycled for five times without an apparent decline of the absorption efficiency.

\subsection{DESs Containing Halogen Anion}

Simulating works were conducted to find a criterion that can explain the solubility order of $\mathrm{SO}_{2}$ at $101 \mathrm{kPa}$ in ILs. Elliott et al. [34] suggested an $\mathrm{SO}_{2}$ affinity order of $\mathrm{Br}^{-}$ $\approx\left[\mathrm{NO}_{3}\right]^{-}>\left[\mathrm{NTf}_{2}\right]^{-}>\left[\mathrm{BF}_{4}\right]^{-}>\left[\mathrm{PF}_{6}\right]^{-}$with a cation of $\left[\mathrm{C}_{4} \mathrm{C}_{1} \mathrm{im}\right]^{+}$. On the basis of the solvation free energy and binding energies of $\mathrm{SO}_{2}$ in ILs, Mondal et al. [35] inferred the $\mathrm{SO}_{2}$ solubility order as $\mathrm{Cl}^{-}>\left[\mathrm{BF}_{4}\right]^{-}>\left[\mathrm{NO}_{3}\right]^{-}>\left[\mathrm{PF}_{6}\right]^{-}>\left[\mathrm{NTf}_{2}\right]^{-}$. Notably, simulation results suggested that halogen anions have stronger potential to physically capture $\mathrm{SO}_{2}$ than any other anions.

Han et al. [36] investigated the $\mathrm{SO}_{2}$ absorption capacities of ChCl:glycerol(Gly) DESs with different molar ratios (from 1:1 to 1:4). The absorption amount is decreased with the increase of the molar ratio of $\mathrm{Gly}$ to $\mathrm{ChCl}$, which implies that $\mathrm{ChCl}$ is a major component of absorption. For example, the solubility of $\mathrm{SO}_{2}$ in ChCl:Gly DES (1:1) is $0.678 \mathrm{~g} \mathrm{SO}_{2} / \mathrm{g}$ DES, which is much higher than that of ChCl:Gly DES (1:2, $0.482 \mathrm{~g} \mathrm{SO}_{2} / \mathrm{g}$ DES), at 293.15 $\mathrm{K}$ and $101 \mathrm{kPa}$. The entire absorption process was completed in $10 \mathrm{~min}$ and the absorbed $\mathrm{SO}_{2}$ could be easily released at a relatively low temperature of $323.15 \mathrm{~K}$ within $20 \mathrm{~min} .{ }^{1} \mathrm{H}$ and ${ }^{13} \mathrm{C}$ NMR analyses were conducted to investigate the mechanism of absorption. The investigation concluded that $\mathrm{ChCl}$ : Gly DESs interacted with $\mathrm{SO}_{2}$ physically, as there is no new peak and no significant peak shift after $\mathrm{SO}_{2}$ capture. However, it still retained the absorptive capacity of $0.153 \mathrm{~g} \mathrm{SO}_{2} / \mathrm{g}$ DES at $10 \mathrm{kPa}$, which is much better than that of most physical absorption DESs and attracted extensive attention.

$\mathrm{Ab}$ initio molecular dynamics (AIMD) and density functional theory (DFT) have been used to investigate the interaction between $\mathrm{SO}_{2}$ molecules and ChCl:Gly DESs [37,38]. A strong interaction between $\mathrm{Cl}^{-}$and $\mathrm{SO}_{2}$ was observed by different methods. The results showed that an electron is transferred from $\mathrm{ChCl}$ : Gly DES to $\mathrm{SO}_{2}$ during the direct interaction between $\mathrm{S}$ and $\mathrm{Cl}$ atoms, and accompanied a disruption of the anion-OH network and nonpolar-nonpolar network, which can explain the dramatic drop in viscosity. Charge transfer interaction is believed to play an important role in $\mathrm{SO}_{2}$ absorption. The interac- 
tion energies were calculated by the different models and the value ranged from -28.45 to $-60.25 \mathrm{~kJ} / \mathrm{mol}$, which is a moderate interaction for $\mathrm{SO}_{2}$ absorption. It means that the interactions are very sensitive to the solvent structure and easy to regenerate, which is consistent with the low regeneration temperature and high desorption rate in Han's work [36].

Due to the excellent property and high capacity of $\mathrm{SO}_{2}$, more and more DESs containing halogen anions were designed and synthesized. Wei et al. [39] determined the absorption capacities of $\mathrm{SO}_{2}$ in four kinds of $\mathrm{ChCl}$-based DESs, including $\mathrm{ChCl}$ : ethylene glycol (EG) DES (1:2), ChCl:malonic acid (MA) DES (1:1), ChCl:UE DES (1:2), and $\mathrm{ChCl}$ :thiourea DES (1:1) at different temperatures and $\mathrm{SO}_{2}$ partial pressures. The $\mathrm{SO}_{2}$ absorption capacities of these DESs at $293 \mathrm{~K}$ and $101 \mathrm{kPa}$ followed the order of $\mathrm{ChCl}$ :thiourea $\left(1: 1,2.96 \mathrm{~mol} \mathrm{SO}_{2} / \mathrm{mol} \mathrm{DES}\right)>\mathrm{ChCl}: \mathrm{EG}\left(1: 2,2.88 \mathrm{~mol} \mathrm{SO}_{2} / \mathrm{mol} \mathrm{DES}\right)>\mathrm{ChCl}$ MA $(1: 1,1.88$ mol SO $2 / \mathrm{mol} \mathrm{DES})>\mathrm{ChCl}: \mathrm{UE}\left(1: 2,1.41 \mathrm{~mol} \mathrm{SO}_{2} / \mathrm{mol} \mathrm{DES}\right)$. At atmospheric pressure, the gravimetric capacity of $\mathrm{ChCl}: \mathrm{EG}\left(1: 2,0.70 \mathrm{~g} \mathrm{SO}_{2} / \mathrm{g}\right.$ DES) was comparable to that of ChCl:Gly $\left(1: 1,0.678 \mathrm{~g} \mathrm{SO}_{2} / \mathrm{g}\right.$ DES), but lower than that of $\mathrm{ChCl}$ :thiourea $\left(1: 1,0.88 \mathrm{~g} \mathrm{SO}_{2} / \mathrm{g}\right.$ DES). However, this order would be totally different at $20 \mathrm{kPa}$, i.e., $\mathrm{ChCl}: \mathrm{EG}(1: 2,0.65 \mathrm{~mol}$ $\left.\mathrm{SO}_{2} / \mathrm{mol} \mathrm{DES}\right)>\mathrm{ChCl}: \mathrm{UE}\left(1: 2,0.56 \mathrm{~mol} \mathrm{SO}_{2} / \mathrm{mol}\right.$ DES $)>\mathrm{ChCl}$ :thiourea $(1: 1,0.30 \mathrm{~mol}$ $\left.\mathrm{SO}_{2} / \mathrm{mol} \mathrm{DES}\right)>\mathrm{ChCl}$ :MA $\left(1: 1,0.28 \mathrm{~mol} \mathrm{SO}_{2} / \mathrm{mol} \mathrm{DES}\right)$. The mole absorptive capacity of ChCl:EG DES (1:2) was more than two times higher than that of ChCl:thiourea DES (1:1), which means that hydroxyl functional groups are more conducive to absorbing $\mathrm{SO}_{2}$ under a low pressure. Deng et al. [40] further improved the absorption capacity of DESs by selecting a more polar organic acid levulinic acid (LA) as HBD compared to polyols, paired with a variety of HBAs. Such as choline acetyl chloride (ChAC), tetraethylammoniumchloride (TEAC), tetrabutylammonium chloride (TBAC), 1-ethyl-3-methylimidazolium chloride $(\mathrm{EmimCl})$. The effect of these HBAs on absorption capacity was ordered as TEAC $>\mathrm{ChAC}>\mathrm{ChCl}>\mathrm{TBAC}$.

\subsection{Imidazolium-Based DESs}

It is reported that imidazolium-based ILs exhibited considerable $\mathrm{SO}_{2}$ absorption capacity. Therefore, Yang et al. [41-43] designed a series of EmimCl-based DESs, including EmimCl:EG DES (1:1), EmimCl:triethylene glycol(TEG) DES (1:1), and EmimCl:succinonitrile (SN) DES (1:1), for efficient $\mathrm{SO}_{2}$ capture and obtained the corresponding absorption capacity of $1.03,0.91$, and $1.13 \mathrm{~g} \mathrm{SO}_{2} / \mathrm{g}$ DES, respectively, at $293.15 \mathrm{~K}$ and $101 \mathrm{kPa}$. It showed that the efficiency of imidazolium cation is better than that of ammonium. This can be interpreted as the $\pi \cdots \pi$ interaction between $\mathrm{SO}_{2}$ and imidazole ring. The effect of HBD in DESs for $\mathrm{SO}_{2}$ capture was ordered as succinonitrile $>\mathrm{EG}>\mathrm{TEG}$. The $\mathrm{SO}_{2}$ solubility in EmimCl:TEG DESs with different molar ratios (from 6:1 to 1:1) were determined, as shown in Figure 1. The $\mathrm{SO}_{2}$ uptake in EmimCl:TEG DESs increased by $\sim 24 \%$ from 1:1 to $4: 1$, whereas only $4 \%$ increment was observed at a $6: 1$ ratio. When the molar ratio is larger than 1:4, the absorption capacity remains almost unchanged. It was demonstrated that there is a limit to increase the absorptive capacity by the increase of the molar ratio of effective absorption components. Considering the cost and absorptive capacity, there is an optimal molar ratio. With the optimal molar ratio, the absorption capacities of EmimCl:EG DES (1:2) and EmimCl:TEG DES (1:4) were 1.03 and $1.20 \mathrm{~g} \mathrm{SO}_{2} / \mathrm{g}$ DES, respectively, at $293.15 \mathrm{~K}$ and $101 \mathrm{kPa}$. It is especially noted that EmimCl:SN DES (1:1) can capture $0.120 \mathrm{~g}$ $\mathrm{SO}_{2} / \mathrm{g}$ DES at 2000 ppm, while EmimCl:EG DES (1:1) can only absorb $0.047 \mathrm{~g} \mathrm{SO}_{2} / \mathrm{g}$ DES at the same conditions. Furthermore, all the $\mathrm{SO}_{2}$ captured by EmimCl:EG DES (1:2) can be desorbed at $313.15 \mathrm{~K}$ within $50 \mathrm{~min}$, which is lower than the desorption temperature of EmimCl:SN DES (353.15 K) and EmimCl:TEG (373.15 K). 


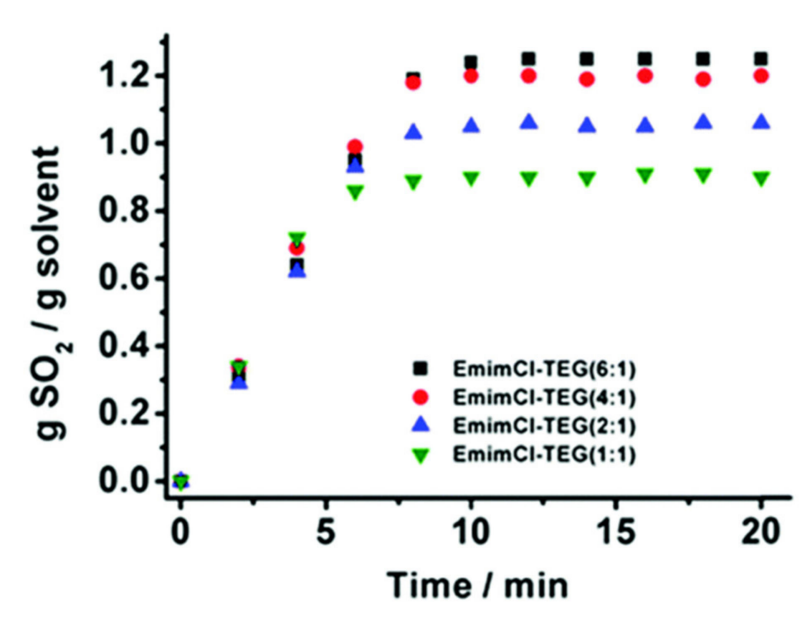

Figure 1. Comparison of $\mathrm{SO}_{2}$ absorption by EmimCl:TEG DESs with different molar ratios as a function of time at $293.15 \mathrm{~K}$ and $101 \mathrm{kPa}$ (Reprinted with permission from Ref[42]. Copyright (2018) The Royal Society of Chemistry).

The effect of HBAs and HBDs in DESs was further investigated by Tantai et al [44]. As shown in Figure 2, the gravimetric $\mathrm{SO}_{2}$ absorption capacities of ethylenurea (EU) and 1,3dimethylurea (DMU)-based DESs with various HBAs displayed the same trend: EmimCl $>\mathrm{BmimCl}>\mathrm{BmimBr}>\mathrm{TBAC} \sim \mathrm{P}_{4444} \mathrm{Cl}$. Among them, the DESs with imidazolium salts as HBAs exhibited lower viscosities than those containing TBAC or $\mathrm{P}_{4444} \mathrm{Cl}$. After $\mathrm{SO}_{2}$ absorption, the viscosities of all DESs (188 389 $\mathrm{mPa} \cdot \mathrm{s})$ decreased significantly to below $8 \mathrm{mPa} \cdot \mathrm{s}$, which can be attributed to the disruption of the anion-OH network and nonpolarnonpolar network by the strong interaction between $\mathrm{SO}_{2}$ and $\mathrm{Cl}^{-}$. Moreover, it was also noted that when the $\mathrm{SO}_{2}$ partial pressure decreased to $2 \mathrm{kPa}$ at $298.15 \mathrm{~K}$, the $\mathrm{SO}_{2}$ absorption capacities of EU:BmimCl DES (1:2) could still be retained at $0.25 \mathrm{~g} \mathrm{SO}_{2} / \mathrm{g}$ DES. Using the unit of $\mathrm{mol} \mathrm{SO}_{2} / \mathrm{mol} \mathrm{DES}$, some intrinsic conclusions could be drawn. For instance, the gravimetric absorption capacities of $\mathrm{SO}_{2}$ in EU-based DESs increased, following the order of $\mathrm{EU}: \mathrm{BmimCl}(1: 2)>\mathrm{EU}: \mathrm{BmimCl}(1: 1)>\mathrm{EU}: \mathrm{BmimCl}(2: 1)$ with the values of 1.18, 1.07, and $0.94 \mathrm{~g} \mathrm{SO}_{2} / \mathrm{g}$ DESs, respectively, while the molar capacities of $\mathrm{SO}_{2}$ in EU:BmimCl DES (1:2), EU:BmimCl DES (1:1), and EU:BmimCl DES (2:1) were 8.03, 4.38, and $5.10 \mathrm{~mol} \mathrm{SO}_{2} / \mathrm{mol}$ DESs, respectively. It could be concluded that both HBDs and HBAs took an active part in $\mathrm{SO}_{2}$ capture.
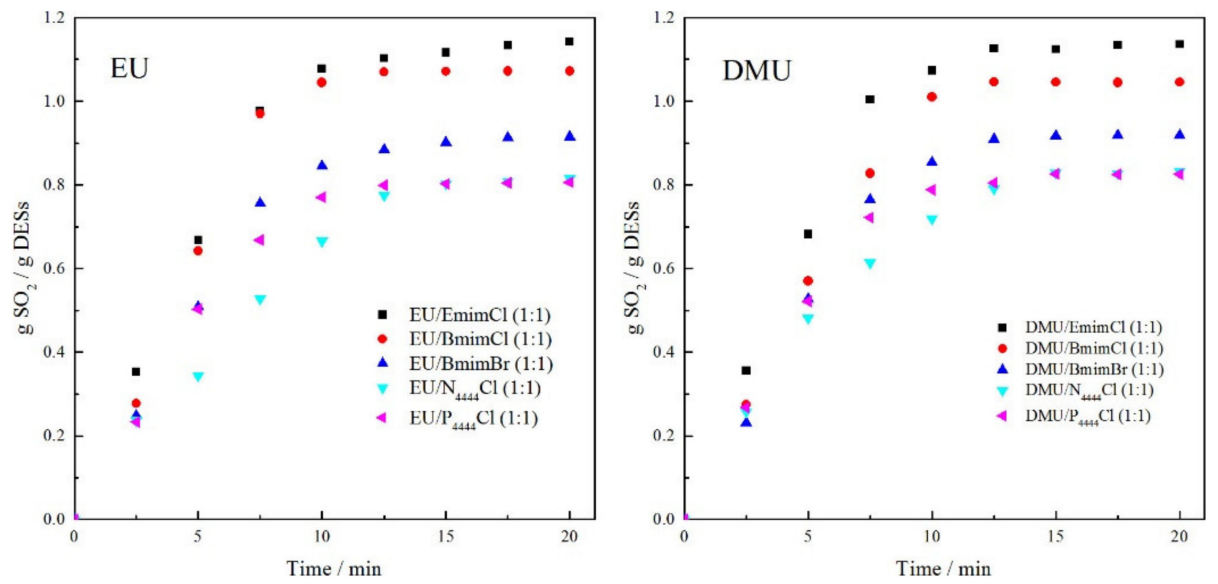

Figure 2. $\mathrm{SO}_{2}$ absorption by DESs with different HBAs at $293.15 \mathrm{~K}$ and $101 \mathrm{kPa}$ (Reprinted with permission from Ref. [44]. Copyright (2019) American Chemical Society).

The effect of the alkyl chain length of imidazole-based DESs on $\mathrm{SO}_{2}$ absorption capacity was investigated by $\mathrm{Hu}$ et al. [45]. The result showed that the absorption capacity of $\mathrm{SO}_{2}$ in a 
mass unit decreased with the increase of alkyl chain length, which may be due to the increase of molecular weight. However, this order would be totally different if the unit was changed into $\mathrm{mol} \mathrm{SO}_{2} / \mathrm{mol}$ DES, i.e., EmimCl: AA > BmimCl:AA > HmimCl:AA with the values of 1.25, 1.17, and $1.02 \mathrm{~g} \mathrm{SO}_{2} / \mathrm{g}_{\text {DESs, corresponding to } 4.01,4.28,4.16 \mathrm{~mol} \mathrm{SO}} / \mathrm{mol} \mathrm{DES}_{\text {. EmimCl:AA }}$ performed the highest gravimetric absorption capacity and $\mathrm{BmimCl}$ :AA performed the highest molar absorption capacity. However, the effect of alkyl chain length on absorptive capacity became a minor factor with the decrease of $\mathrm{SO}_{2}$ partial pressure. The absorptive capacities of $\mathrm{SO}_{2}$ in EmimCl:AA DES (1:1), BmimCl:AA DES (1:1), and HmimCl:AA DES (1:1) were 0.46 (1.48), 0.44 (1.61), 0.38 (1.55) $\mathrm{g} \mathrm{SO}_{2} / \mathrm{g}$ DESs $\left(\mathrm{mol} \mathrm{SO}_{2} / \mathrm{mol} \mathrm{DES}\right)$ at $101 \mathrm{kPa}$ A series of DESs paired EmimCl with different HDBs was investigated [46,47], including EmimCl:DMU, EmimCl:N-methylurea (MU), EmimCl:thioacetamide(TAA), EmimCl:CPL, and EmimCl:N-Formylmorpholine (NFM). The absorption properties of $\mathrm{SO}_{2}$ in terms of gravimetric absorption are very close in those DESs, distributed from 0.36 to $0.45 \mathrm{~g} \mathrm{SO}_{2} / \mathrm{g}$ DES at $10 \mathrm{kPa}$ and from 1.09 to $1.26 \mathrm{~g} \mathrm{SO}_{2} / \mathrm{g}$ DES at $101 \mathrm{kPa}, 293.15 \mathrm{~K}$, as shown in Table 1 . In general, HBAs of EmimCl-based DESs have a much stronger influence on the solubility of $\mathrm{SO}_{2}$ than the HBDs, which played a vital role in absorption and leaded to the similar absorption capacity of EmimCl-based DESs.

Table 1. $\mathrm{SO}_{2}$ solubility in non-functionalized DESs.

\begin{tabular}{|c|c|c|c|c|c|c|}
\hline DESs & $\begin{array}{l}\text { Molar } \\
\text { Ratio }\end{array}$ & $T / K$ & $\begin{array}{c}\text { Capacity at } 101 \\
\mathrm{kPa}\left(\mathrm{g} \mathrm{SO}_{2} / \mathrm{g} \text { DES) }\right.\end{array}$ & $\begin{array}{l}\text { Capacity at } 10 \mathrm{kPa} \\
\left(\mathrm{g} \mathrm{SO}_{2} / \mathrm{g} \mathrm{DES}\right)\end{array}$ & $\begin{array}{l}\text { Capacity at } \\
\sim 2000 \text { ppm (g } \\
\mathrm{SO}_{2} / \mathrm{g} \text { DES) }\end{array}$ & Ref. \\
\hline ACC:LA & $1: 1$ & 293.15 & 0.567 & & & [40] \\
\hline AA:KSCN & $3: 1$ & 293.15 & 0.588 & & & [31] \\
\hline $\mathrm{AA}: \mathrm{NH}_{4} \mathrm{SCN}$ & $3: 1$ & 293.15 & 0.579 & & & [31] \\
\hline BmimBr:DMU & $1: 1$ & 293.15 & 0.92 & & & [44] \\
\hline BmimBr:EU & $1: 1$ & 293.15 & 0.91 & & & [44] \\
\hline BmimCl:AA & $1: 1$ & 293.15 & $1.17(4.28)^{1}$ & $0.44(1.61)^{1}$ & & [45] \\
\hline BmimCl:DMU & $2: 1$ & 293.15 & 1.14 & 0.42 & $0.26^{3}$ & [44] \\
\hline BmimCl:DMU & $1: 1$ & 293.15 & 1.14 & & & [44] \\
\hline BmimCl:EU & $2: 1$ & 293.15 & 1.18 & 0.42 & $0.25^{3}$ & [44] \\
\hline BmimCl:EU & $1: 1$ & 293.15 & 1.07 & & & [44] \\
\hline BmimCl:EU & $1: 2$ & 293.15 & 0.94 & & & [44] \\
\hline ChCl:EG & $1: 2$ & 293.15 & $0.7(2.88)^{1}$ & $(0.65)^{2}$ & & [39] \\
\hline ChCl:MA & $1: 1$ & 293.15 & $(1.88)^{1}$ & $(0.28)^{2}$ & & [39] \\
\hline ChCl:UE & $1: 2$ & 293.15 & $(1.41)^{1}$ & $(0.56)^{2}$ & & [39] \\
\hline ChCl:Gly & $1: 1$ & 293.15 & 0.678 & 0.153 & & [36] \\
\hline ChCl:Gly & $1: 2$ & 293.15 & 0.482 & 0.077 & & [36] \\
\hline ChCl:Gly & $1: 3$ & 293.15 & 0.38 & 0.053 & & [36] \\
\hline ChCl:Gly & $1: 4$ & 293.15 & 0.32 & 0.046 & & [36] \\
\hline ChCl: LA & $1: 1$ & 293.15 & 0.557 & & & [40] \\
\hline ChCl:thiourea & $1: 1$ & 293.15 & $0.88(2.96)^{1}$ & $(0.3)^{2}$ & & [39] \\
\hline CPL:AA & $1: 1$ & 303.15 & 0.497 & & & [29] \\
\hline CPL:KSCN & $3: 1$ & 293.15 & 0.607 & & & [31] \\
\hline CPL: $\mathrm{NH}_{4} \mathrm{SCN}$ & $3: 1$ & 293.15 & 0.595 & & & [31] \\
\hline CPL:TBAB & $1: 1$ & 298.2 & 0.099 & & & [29] \\
\hline EmimCl:AA & $2: 1$ & 293.15 & $1.39(7.63)^{1}$ & $0.49(2.70)^{1}$ & & [45] \\
\hline EmimCl:AA & $1: 1$ & 293.15 & $1.25(4.01)^{1}$ & $0.46(1.48)^{1}$ & & [45] \\
\hline EmimCl:AA & $1: 2$ & 293.15 & $1.13(4.69)^{1}$ & $0.27(1.12)^{1}$ & & [45] \\
\hline EmimCl:CLAA & $2: 1$ & 293.15 & $1.26(8.00)^{1}$ & $0.45(2.86)^{1}$ & & [47] \\
\hline EmimCl:DMU & $1: 1$ & 293.15 & 1.04 & & & [44] \\
\hline
\end{tabular}


Table 1. Cont.

\begin{tabular}{|c|c|c|c|c|c|c|}
\hline DESs & $\begin{array}{l}\text { Molar } \\
\text { Ratio }\end{array}$ & $T / K$ & $\begin{array}{c}\text { Capacity at } 101 \\
\mathrm{kPa}\left(\mathrm{g} \mathrm{SO}_{2} / \mathrm{g} \text { DES) }\right.\end{array}$ & $\begin{array}{l}\text { Capacity at } 10 \mathrm{kPa} \\
\left(\mathrm{g} \mathrm{SO}_{2} / \mathrm{g} \mathrm{DES}\right)\end{array}$ & $\begin{array}{c}\text { Capacity at } \\
\sim 2000 \text { ppm (g } \\
\mathrm{SO}_{2} / \mathrm{g} \text { DES) }\end{array}$ & Ref. \\
\hline EmimCl:DMU & $2: 1$ & 293.15 & $1.22(7.26)^{1}$ & $0.43(2.50)^{1}$ & & [47] \\
\hline EmimCl:EG & $2: 1$ & 293.15 & 1.15 & 0.42 & & [41] \\
\hline EmimCl:EG & $1: 1$ & 293.15 & 1.03 & 0.31 & & [41] \\
\hline EmimCl:EG & $1: 2$ & 293.15 & 0.82 & 0.22 & & [41] \\
\hline EmimCl:EPyBr & $3: 1$ & 293.15 & 1.395 & 0.698 & 0.17 & [46] \\
\hline EmimCl:EPyBr & $2: 1$ & 293.15 & 1.336 & 0.662 & 0.162 & [46] \\
\hline EmimCl:EPyBr & $1: 1$ & 293.15 & 1.286 & 0.627 & 0.155 & [46] \\
\hline EmimCl:EU & $1: 1$ & 293.15 & 1.14 & & & [44] \\
\hline EmimCl:MU & $2: 1$ & 293.15 & $1.09(6.25)^{1}$ & $0.36(2.06)^{1}$ & & [47] \\
\hline EmimCl:SAA & $2: 1$ & 293.15 & $1.18(6.79)^{1}$ & $0.37(2.13)^{1}$ & & [47] \\
\hline EmimCl:SN & $1: 1$ & 293.15 & 1.13 & & 0.12 & [43] \\
\hline EmimCl:SN & $1: 2$ & 293.15 & 0.96 & & 0.085 & [43] \\
\hline EmimCl:SN & $1: 4$ & 293.15 & 0.79 & & 0.047 & [43] \\
\hline EmimCl:TEG & $6: 1$ & 293.15 & 1.25 & 0.54 & & [42] \\
\hline EmimCl:TEG & $4: 1$ & 293.15 & 1.2 & 0.5 & & [42] \\
\hline EmimCl:TEG & $2: 1$ & 293.15 & 1.06 & 0.38 & & [42] \\
\hline EmimCl:TEG & $1: 1$ & 293.15 & 0.91 & 0.31 & & [42] \\
\hline EmimCl:NFM & $1: 1$ & 293.15 & & 0.429 & & [46] \\
\hline HmimCl:AA & $1: 1$ & 293.15 & $1.02(4.16)^{1}$ & $0.38(1.55)^{1}$ & & [45] \\
\hline TBAC:DMU & $1: 1$ & 293.15 & 0.83 & & & [44] \\
\hline TBAC:EU & $1: 1$ & 293.15 & 0.81 & & & [44] \\
\hline $\mathrm{P}_{4444} \mathrm{Cl}: \mathrm{DMU}$ & $1: 1$ & 293.15 & 0.83 & & & [44] \\
\hline $\mathrm{P}_{4444} \mathrm{Cl}: \mathrm{EU}$ & $1: 1$ & 293.15 & 0.81 & & & [44] \\
\hline TBAB:LA & $1: 1$ & 293.15 & 0.547 & & & [40] \\
\hline TBAC: LA & $1: 1$ & 293.15 & 0.541 & & & [40] \\
\hline TEAB: LA & $1: 1$ & 293.15 & 0.622 & & & [40] \\
\hline TEAC: LA & $1: 1$ & 293.15 & 0.625 & & & [40] \\
\hline Urea: $\mathrm{NH}_{4} \mathrm{SCN}$ & $3: 1$ & 303.15 & 0.372 & & & [31] \\
\hline
\end{tabular}

${ }^{1}$ Data in brackets are the molar fraction. ${ }^{2}$ At $20 \mathrm{kPa} .{ }^{3}$ At $2 \mathrm{kPa}$.

Kang et al. [48] developed a new type of DES formed by EmimCl and N-ethylpyridinium bromide (EPyBr), in which halogen anions were introduced into both HBA and HBD. Although the viscosity of EmimCl:EPyBr was $2260 \mathrm{mPa} \cdot \mathrm{s}$ before absorption, the viscosity dropped rapidly from 2260 to $6 \mathrm{mPa} \cdot \mathrm{s}$ with the dissolution of $\mathrm{SO}_{2}$, owing to the strong charge transfer interactions between $\mathrm{SO}_{2}$ and the anions $\mathrm{Cl}^{-}$and $\mathrm{Br}^{-}$. The $\mathrm{SO}_{2}$ absorption capacity of EmimCl:EPyBr with a molar ratio of 3:1 was $0.698 \mathrm{~g} \mathrm{SO}_{2} / \mathrm{g}$ DES at $293.15 \mathrm{~K}$ and $10 \mathrm{kPa}$, which was higher than the results of most DESs and ILs reported previously. Moreover, it could still absorb $0.170 \mathrm{~g} \mathrm{SO}_{2} / \mathrm{g}$ $\mathrm{DES}$ at $293.15 \mathrm{~K}$ and an $\mathrm{SO}_{2}$ concentration of $2000 \mathrm{ppm}$ and the regeneration of EmimCl:EPyBr could be achieved at $363.15 \mathrm{~K}$ within $45 \mathrm{~min}$ by blowing $\mathrm{N}_{2}$.

\section{Functionalized DESs for $\mathrm{SO}_{2}$ Capture}

There are two methods to obtain functionalized DESs for $\mathrm{SO}_{2}$ capture. Due to the strong acidity of $\mathrm{SO}_{2}$, it is expected to reach a high capacity by selecting organic compounds with alkaline functional groups as HBA or HBD, such as alcohol amines, polyamines, and azoles. Using conjugate bases of weak acids as HBAs, such as carboxylated and phenolated ones, is another way to enhance $\mathrm{SO}_{2}$ solubility. Basicity is significant during the structure property designing of DESs for enhancing $\mathrm{SO}_{2}$ solubility. It is reported that $\mathrm{SO}_{2}$ capture by DESs could be tuned by the basicity of components. Recently, by mixing the halogen salt HBAs which can efficiently absorb $\mathrm{SO}_{2}$ through physical interaction mentioned above and functionalized HBDs can achieve higher absorption capacity and desorption rate than DESs, which relies mainly on physical or chemical absorption. The reported functionalized DESs for $\mathrm{SO}_{2}$ capture and their $\mathrm{SO}_{2}$ capacities at different conditions are included in Table 2. 


\subsection{Azole-Based Functionalized DESs}

Azoles, such as imidazole (Im), triazole (Tri), tetrazole (Tetz), are definitely able to interact with $\mathrm{SO}_{2}$ based on Lewis acid-base reaction in a form of N..S bonding. Due to the excellent property and high capacity of $\mathrm{SO}_{2}$ capture, numerous azole-based functionalized DESs were designed and synthesized. In 2013, Liu et al. [29] reported CPL:Im DES (1:1). The solubility of $\mathrm{SO}_{2}$ in CPL:Im DES (1:1) is $0.624 \mathrm{~g} \mathrm{SO}_{2} / \mathrm{g}$ DES at $303.15 \mathrm{~K}$ and $101 \mathrm{kPa}$. During the absorption process, the transplant and colorless CPL:Im DES (1:1) turned to a yellowish paste, which can be interpreted by the chemical reaction between imidazole and $\mathrm{SO}_{2}$. Deng et al. [49] synthesized the azole-based DES with acetyl choline chloride (ACC) as HBA. The results showed that the structure of azole has evident influence on the $\mathrm{SO}_{2}$ absorption capacity. As shown in Table 2, ACC:Im DES possessed higher absorption capacity of $\mathrm{SO}_{2}$ than ACC:Tri DES, which is related to the higher basicity of the imidazole than that of 1,2,4-triazole. ACC:Im DES with molar ratio of 1:3 exhibited the highest absorption capacity of $0.383 \mathrm{~g} \mathrm{SO}_{2} / \mathrm{g}$ DES at $0.1 \mathrm{bar}$ and $303.15 \mathrm{~K}$. The higher absorption capacity of ACC:Im than that of Im:Gly [50] could be attributed to the stronger physical absorption of chloride anion. However, the two DES performed differently in desorption experiments. For the DES of ACC:Tri (1:1), the absorbed $\mathrm{SO}_{2}$ could be completely stripped out by bubbling $\mathrm{N}_{2}$ at $363.15 \mathrm{~K}$, while there was approximately $0.025 \mathrm{~g} \mathrm{SO}_{2} / \mathrm{g}$ DES still remained after regeneration for ACC:Im DES (1:2).

The effect of substituents on imidazole ring was studied by Wu et al. [50]. They designed Im:Gly, 2-methylimidazole (2-Me):Gly, 2-ethylimidazole (2-Et):Gly and 2-propylimidazole (2$\mathrm{Pr})$ :Gly for efficient $\mathrm{SO}_{2}$ capture at $313.15 \mathrm{~K}, 2 \mathrm{kPa}$ and obtained the corresponding absorption capacity of $0.253,0.246,0.241,0.225 \mathrm{~g} \mathrm{SO}_{2} / \mathrm{g}$ DES. The result demonstrated that the alkyl connected to the $\mathrm{N}(3)$ atom has almost no effect on the molar absorption capacities which reach 1:1 stoichiometry. However, with the increase of the molecular weight of HBAs, the mass absorption decreased. The $\mathrm{SO}_{2}$ absorption mechanism was proposed after the saturated system was characterized by ${ }^{1} \mathrm{H}$ NMR and FTIR, the acidic $\mathrm{SO}_{2}$ reacted with the basic $\mathrm{N}$ atom in Im through strong acid-base reaction, which leaded to an increase in viscosity from 149 $\mathrm{mPa} \cdot \mathrm{s}$ to $470 \mathrm{mPa} \cdot \mathrm{s}$ for Im:Gly DES (1:2) at $313.15 \mathrm{~K}$ and incomplete desorption. Considering that flue gas contains a large amount of water (e.g., $8 \mathrm{vol} \%$ ), which does not just act as a hydrogen bond donor such as Gly, but also can increase the absorption capacity per mass unit and significantly reduce the viscosity due to its low molecular weight, Wu et al. [51] mixed 2-Me:Gly, 2-Et:Gly and 2-Pr with $\mathrm{H}_{2} \mathrm{O}$ to synthesize three kinds of cheap and low viscosity functional DESs. The absorption results showed that the mole absorption capacities of three DESs were all about $1 \mathrm{~mol} \mathrm{SO} / 2 / \mathrm{mol} \mathrm{HBA}$ at $313 \mathrm{~K}$ and $2 \mathrm{kPa}$. Im: $\mathrm{H}_{2} \mathrm{O}$ DES (1:4) showed a mass absorption capacity of $0.331 \mathrm{~g} \mathrm{SO}_{2} / \mathrm{g}$ DES, which is higher than that of most DESs reported in the literature.

Inspired by previous reports, BmimCl-based DESs and azole-based DESs could efficiently absorb $\mathrm{SO}_{2}$ through physisorption and chemisorption. A series of imidazole derivatives were selected as HBDs, including imidazole, 4-methylimidazole $\left(4 \mathrm{CH}_{3}\right.$ - $\left.\mathrm{Im}\right)$, pyrazole (Pyr), tetrazole, and benzimidazole (Ben-Im), paired with four different types of salts containing halogen anions to synthesize DESs by Tantai et al. [52]. $\mathrm{SO}_{2}$ absorption capacities of TBAC with different HBDs at $293.2 \mathrm{~K}$ and $101.3 \mathrm{kPa}$ were ordered as TBAC: $4 \mathrm{CH}_{3}-\operatorname{Im}(1: 2)>$ TBAC:Im (1:2) > TBAC:Ben-Im (1:2) > TBAC:Pyr (1:2) > TBAC:Tetz (1:2), corresponding with the basicity of HBDs. For $4 \mathrm{CH}_{3}$-Im-based DESs, the effect of HBAs on absorption capacity was ordered as BmimCl: $4 \mathrm{CH}_{3}-\mathrm{Im}(1: 2)>\mathrm{P}_{4444} \mathrm{Cl}: 4 \mathrm{CH}_{3}$-Im (1:2) TBAC:4 $\mathrm{CH}_{3}-\operatorname{Im}(1: 2)>$ TBAC:Im (1:2) > TBAB:Im (1:2). The investigation concluded that $\mathrm{SO}_{2}$ capacity could be tuned by different substituents on the imidazole ring (high basicity $>$ low basicity), the types of cations (e.g., imidazolium $>\mathrm{TBA} \approx \mathrm{TBP}$ ) and anions (e.g., $\mathrm{Cl}^{-}>\mathrm{Br}^{-}$). BmimCl:4CH $\mathrm{CH}_{3}$-Im DES (1:2) exhibited a better absorption performance compared to $\mathrm{P}_{4444} \mathrm{Cl}_{4} 4 \mathrm{CH}_{3}$-Im DES (1:2), which indicated that imidazole ring also participated in $\mathrm{SO}_{2}$ absorption. As shown in Figure 3, the effect of $\mathrm{SO}_{2}$ partial pressure on the absorption capacity was dramatical, the $\mathrm{SO}_{2}$ absorption capacity of $\mathrm{BmimCl} 4 \mathrm{CH}_{3}-\mathrm{Im} \mathrm{DES}(1: 2)$ increased sharply from 2 to $10 \mathrm{kPa}$ with the value increased from 0.244 to $0.613 \mathrm{~g} \mathrm{SO}_{2} / \mathrm{g}$ 
DES and then increased linearly with the pressure from 10 to $101.3 \mathrm{kPa}\left(1.42 \mathrm{~g} \mathrm{SO}_{2} / \mathrm{g}\right.$ DES), which implied that the chemical absorption is efficient for the $\mathrm{SO}_{2}$ capture at low partial pressures $(2 \sim 10 \mathrm{kPa})$ and then the physical absorption played a dominant role as the pressure increases $(10 \sim 101.3 \mathrm{kPa})$. An interesting phenomenon accompanied by the absorption process is that the colorless solvent gradually turned to brown in CPL:Im DES (1:1), which was also observed by Liu et al. [29]. Based on previous research, Tantai et al. put forward a novel strategy to prepare ternary functionalized DESs capable of chemically binding ultralow concentration (2000 ppm) $\mathrm{SO}_{2}$ in the flue gas, by mixing low-cost azole derivatives with ternary EU:BmimCl DESs [53]. By comparing the absorption capacity of ternary EU:4- $\mathrm{CH}_{3}-\mathrm{Im}: \mathrm{BmimCl}$ DESs (1:1:1, 2:1:1, 1:2:1, and 1:1:2) with binary DESs, including EU:BmimCl DES (1:1), $\mathrm{CH}_{3}-\mathrm{Im}: \mathrm{BmimCl}$ DES (1:1) and 4- $\mathrm{CH}_{3}$-Im:BmimCl DES (2:1), as shown in Table 2. Several conclusions can be drawn: (1) The introduction of 4- $\mathrm{CH}_{3}$-Im or Im as secondary HBDs could effectively increase the absorption capacity, which was little affected by introducing pyrazole, triazole and tetrazole. (2) EU also participated in the absorption process as an active component, as the molar absorption capacity of EU:4- $\mathrm{CH}_{3}$ Im:BmimCl DES (1:1:1) were higher than that of $\mathrm{CH}_{3}$-Im:BmimCl DES (1:1). (3) EU could remarkably regulate the interaction between $\mathrm{SO}_{2}$ and ternary DESs. $4-\mathrm{CH}_{3}-\mathrm{Im}: \mathrm{BmimCl}$ DES (1:1) turned into a gel during the $\mathrm{SO}_{2}$ absorption, while EU:4- $\mathrm{CH}_{3}-\mathrm{Im}: \mathrm{BmimCl}$ DES (1:1:1) could still be liquid after absorption. The gravimetric absorption capacities of ternary EU:4- $\mathrm{CH}_{3}$-Im:BmimCl DESs (1:1:1, 1:2:1, and 1:1:2) reached 0.294, 0.347, and $0.255 \mathrm{~g} \mathrm{SO}_{2} / \mathrm{g}$ DES, respectively, at $298 \mathrm{~K}$ and $2000 \mathrm{ppm}$ of $\mathrm{SO}_{2}$, corresponding to $1.58,2.29$, and $2.07 \mathrm{~mol}$ $\mathrm{SO}_{2} / \mathrm{mol}$ DES.

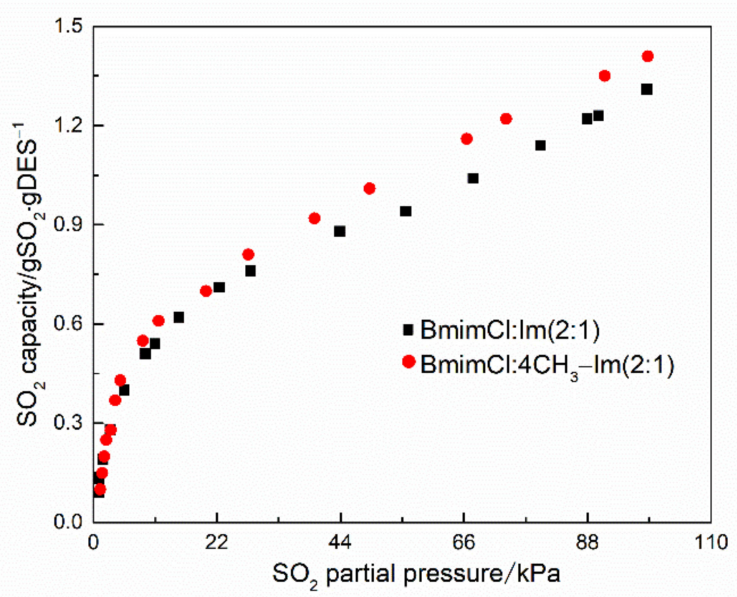

Figure 3. Effect of $\mathrm{SO}_{2}$ partial pressure on the $\mathrm{SO}_{2}$ capture at $293.2 \mathrm{~K}$ (Reprinted with permission from Ref. [52]. Copyright (2018) American Chemical Society).

\subsection{Other Kinds of Functionalized DESs}

Cui et al. [54] designed a series of functionalized DESs based on piperazinium cation, which were prepared by mixing 1-hydroxyethyl-1,4-dimethyl-piperazinium bromide (PPZBr) with Gly at different molar ratios. The absorption capacities of PPZBr:Gly with different molar ratios were ranged from 0.08 to $0.1 \mathrm{~g} \mathrm{SO}_{2} / \mathrm{g}$ DES at $293.15 \mathrm{~K}$ and $1 \mathrm{kPa}$, corresponding to $0.96 \sim 0.99 \mathrm{~mol} \mathrm{SO}_{2} / \mathrm{mol} \mathrm{DES}$, which indicated that the molar ratio did not significantly affect the adsorption capacity under low $\mathrm{SO}_{2}$ partial pressures. The change of viscosity along with the absorption of $\mathrm{SO}_{2}$ under atmospheric conditions was investigated, as shown in Figure 4. It can be seen that the viscosity of each PPZBr:Gly DES dramatically increased in first $5 \mathrm{~min}$ and then decreased sharply with a further increase of $\mathrm{SO}_{2}$ dissolution. This phenomenon is similar to the finding of Wu et al. [55] and Zhang et al. [56] on $\mathrm{SO}_{2}$ absorption by ILs. The results of viscosity experiments proved that PPZBr:Gly efficiently absorbed $\mathrm{SO}_{2}$ through a combination of chemical and physical interactions. 


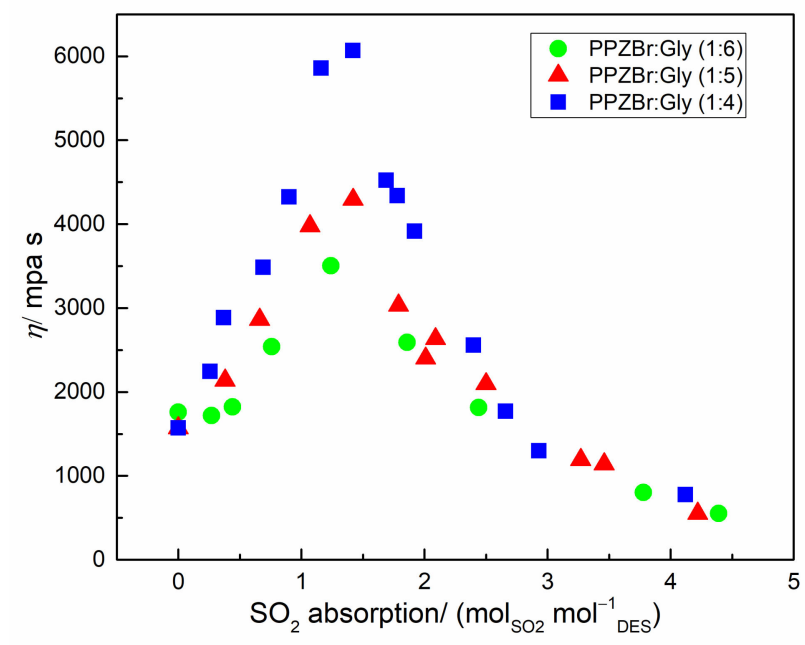

Figure 4. Viscosity of DESs as a function of the absorption amount of $\mathrm{SO}_{2}$. (Reprinted with permission from Ref. [54]. Copyright (2019) American Chemical Society).

Wu et al. [57] reported a new type of internal salt type DES based on betaine (Bet) or L-carnitine (L-car), with the ability to chemically absorb $\mathrm{SO}_{2}$ by strong acid-base reactions between the acidic $\mathrm{SO}_{2}$ and Lewis-based $\mathrm{COO}^{-}$. The absorption capacity of L-car:EG with a molar ratio of $1: 3$ was $0.151 \mathrm{~g} \mathrm{SO}_{2} / \mathrm{g} \mathrm{DES}$ at $2 \mathrm{kPa}, 313.15 \mathrm{~K}$. However, due to the strong acid-base reactions between the acidic $\mathrm{SO}_{2}$ and Lewis-based $\mathrm{COO}^{-}$, the absorbed $\mathrm{SO}_{2}$ cannot be completely released.

Table 2. $\mathrm{SO}_{2}$ solubility in functionalized DESs.

\begin{tabular}{|c|c|c|c|c|c|c|c|}
\hline DESs & $\begin{array}{l}\text { Molar } \\
\text { Ratio }\end{array}$ & $T / K$ & $\begin{array}{c}\text { Capacity at } 101 \\
\mathrm{kPa} \mathrm{g} \mathrm{SO}_{2} / \mathrm{g} \text { DES }\end{array}$ & $\begin{array}{l}\text { Capacity at } 10 \mathrm{kPa} \\
\mathrm{g} \mathrm{SO}_{2} / \mathrm{g} \mathrm{DES}\end{array}$ & $\begin{array}{l}\text { Capacity at } 2 \mathrm{kPa} \\
\mathrm{g} \mathrm{SO}_{2} / \mathrm{g} \mathrm{DES}\end{array}$ & $\begin{array}{c}\text { Capacity at } \\
\sim 2000 \text { ppm g } \\
\mathrm{SO}_{2} / \mathrm{g} \text { DES }\end{array}$ & Ref. \\
\hline ACC:Im & $1: 2$ & 303.15 & 0.989 & 0.381 & & & [49] \\
\hline ACC:Im & $1: 3$ & 303.15 & & 0.383 & & & [49] \\
\hline ACC:Tri & $1: 1$ & 303.15 & & 0.227 & & & [49] \\
\hline Bet:EG & $1: 3$ & 313.15 & $0.366(1.735)^{1}$ & & $0.0701(0.332)^{1}$ & & [57] \\
\hline $\begin{array}{l}\text { BmimCl:4- } \\
\mathrm{CH}_{3} \text {-Im }\end{array}$ & $1: 2$ & 293.2 & 1.42 & 0.613 & & 0.244 & [52] \\
\hline $\begin{array}{l}\mathrm{BmimCl}: 4- \\
\mathrm{CH}_{3}-\mathrm{Im}\end{array}$ & $1: 1$ & 293.2 & 1.31 & & & & [52] \\
\hline $\begin{array}{l}\text { BmimCl:4- } \\
\mathrm{CH}_{3}-\mathrm{Im}\end{array}$ & $1: 1$ & 293.15 & & & $0.354(1.42)^{1}$ & & [53] \\
\hline $\begin{array}{l}\mathrm{BmimCl}: 4- \\
\mathrm{CH}_{3}-\mathrm{Im}\end{array}$ & $2: 1$ & 293.15 & & & $0.258(1.37)^{1}$ & & [53] \\
\hline BmimCl:Im & $2: 1$ & 293.2 & 1.32 & 0.564 & & 0.225 & [52] \\
\hline BmimCl:Im & $1: 1$ & 293.2 & 1.29 & & & & [52] \\
\hline BmimCl:Im & $1: 2$ & 293.2 & 1.24 & & & & [52] \\
\hline CPL:Im & $1: 1$ & 303.15 & 0.624 & & & & [29] \\
\hline 2-Et:Gly & $1: 2$ & 313.15 & & & 0.241 & & [50] \\
\hline $\begin{array}{l}\mathrm{EU}: 4-\mathrm{CH}_{3}^{-} \\
\mathrm{Im}: \mathrm{BmimCl}\end{array}$ & 1:1:1 & 293.15 & & & $0.294(1.58)^{1}$ & & [53] \\
\hline $\begin{array}{l}\text { EU:4- } \mathrm{CH}_{3}- \\
\mathrm{Im}: \mathrm{BmimCl}\end{array}$ & $2: 1: 1$ & 293.15 & & & $0.232(1.54)^{1}$ & & [53] \\
\hline $\begin{array}{l}\text { EU:4- } \mathrm{CH}_{3}- \\
\mathrm{Im}: \mathrm{BmimCl}\end{array}$ & $1: 2: 1$ & 293.15 & & & $0.347(2.29)^{1}$ & & [53] \\
\hline $\begin{array}{l}\text { EU:4-CH }{ }_{3-}^{-} \\
\text {Im:BmimCl }\end{array}$ & $1: 1: 2$ & 293.15 & & & $0.255(2.07)^{1}$ & & [53] \\
\hline Im:Gly & $1: 2$ & 313.15 & & & 0.253 & 0.211 & [50] \\
\hline $\mathrm{Im}: \mathrm{H}_{2} \mathrm{O}$ & $1: 4$ & 313.15 & $0.369(1.208)^{1}$ & & $0.331(1.083)^{1}$ & $0.267(0.873)^{1}$ & [51] \\
\hline
\end{tabular}


Table 2. Cont.

\begin{tabular}{|c|c|c|c|c|c|c|c|}
\hline DESs & $\begin{array}{l}\text { Molar } \\
\text { Ratio }\end{array}$ & $T / K$ & $\begin{array}{c}\text { Capacity at } 101 \\
\mathrm{kPa} \mathrm{g} \mathrm{SO}_{2} / \mathrm{g} \text { DES }\end{array}$ & $\begin{array}{l}\text { Capacity at } 10 \mathrm{kPa} \\
\mathrm{g} \mathrm{SO}_{2} / \mathrm{g} \text { DES }\end{array}$ & $\begin{array}{l}\text { Capacity at } 2 \mathrm{kPa} \\
\mathrm{g} \mathrm{SO}_{2} / \mathrm{g} \text { DES }\end{array}$ & $\begin{array}{c}\text { Capacity at } \\
\sim 2000 \text { ppm g } \\
\mathrm{SO}_{2} / \mathrm{g} \text { DES }\end{array}$ & Ref. \\
\hline L-car:EG & $1: 3$ & 313.15 & $0.365(1.979)^{1}$ & & $0.151(0.819)^{1}$ & & [57] \\
\hline 2-Me:Gly & $1: 2$ & 313.15 & & & 0.246 & & [50] \\
\hline $\begin{array}{l}\text { TBAC:4- } \\
\mathrm{CH}_{3}-\mathrm{Im}\end{array}$ & $1: 2$ & 293.2 & 1.04 & & & & [52] \\
\hline TBAC:Im & $1: 2$ & 293.2 & 0.96 & & & & [52] \\
\hline 2-Pr:Gly & $1: 2$ & 313.15 & & & 0.225 & & [50] \\
\hline PPZBr:Gly & $1: 4$ & 298.15 & $0.42(3.97)^{1}$ & $0.15(1.47)^{1}$ & $0.10(0.98)^{2}$ & & [54] \\
\hline PPZBr:Gly & $1: 6$ & 298.15 & $0.35(4.28)^{1}$ & $0.13(1.55)^{1}$ & $0.08(0.99)^{2}$ & & [54] \\
\hline PPZBr:Gly & $1: 5$ & 298.15 & $0.38(4.10)^{1}$ & $0.13(1.43)^{1}$ & $0.09(0.96)^{2}$ & & [54] \\
\hline
\end{tabular}

${ }^{1}$ Data in brackets are the molar fraction. ${ }^{2}$ At $1 \mathrm{kPa}$.

\section{Non-Functionalized DESs for $\mathrm{CO}_{2}$ Capture}

In 2006, Zhu et al. [24] reported that ChCl:urea DES supported on molecular sieves could effectively catalyze the reactions of $\mathrm{CO} 2$ and epoxides. After that a significant number of studies were conducted on the capacity of the choline chloride-based DES for $\mathrm{CO}_{2}$ capture [58-60]. Lu et al. [61] reviewed the choline-based DESs for $\mathrm{CO}_{2}$ separation recently. Thus, $\mathrm{CO}_{2}$ capture by choline chloride-based DESs is not included in this review. Since $\mathrm{CO}_{2}$ is a linear non-polar molecule, it is difficult for $\mathrm{CO}_{2}$ to dissolve in DESs at atmospheric pressure. According to the reported results, high capacity of $\mathrm{CO}_{2}$ physical absorption in non-functionalized DESs is favored with lower temperatures and higher pressures. Later, different combinations of HBDs and HBAs components were tried to optimize the $\mathrm{CO}_{2}$ uptake capacity in DESs but the capacities of all the tested DESs remained in the range of $0.009-0.85 \mathrm{~mol} \mathrm{CO} / \mathrm{kg}$ DES.

Ali et al. [62] studied 17 different types of DESs based on different ammonium and phosphonium salts with five different HBDs, namely EG, Gly, diethanolamine (DEA), triethanolamine (TEA), and monoethanolamine (MEA), for $\mathrm{CO}_{2}$ capture. The solubility values for $\mathrm{CO}_{2}$ in DESs at $298.15 \mathrm{~K}$ and pressures up to $1.0 \mathrm{MPa}$ remained in the range of 0.013-0.0749 $\mathrm{g} \mathrm{CO}_{2} / \mathrm{g}$ DES and 0.0211-0.1441 $\mathrm{mol} \mathrm{CO}_{2} / \mathrm{mol} \mathrm{DES}$, as shown in Table 3. The experimental results demonstrated that the DESs have intricate physical behaviors compared to pure HBA or HBD. Thus, the absorption capacity cannot be simply predicted by considering the contribution effect of its components. For instance, $\mathrm{ChCl}$ :EG DESs had lower $\mathrm{CO}_{2}$ solubility compared to pure EG, while the $\mathrm{CO}_{2}$ solubility in glycerol-based DESs was found to be higher than that in pure glycerol. For ChCl:MEA DES (1:6), the solubility was $0.1096 \mathrm{~mol} \mathrm{CO}_{2} / \mathrm{mol}$ DES, which was nearly two times higher than that in a $30 \mathrm{wt} \%$ MEA aqueous solution at 298.15 $\mathrm{K}$ and $1 \mathrm{MPa}$. However, the gravimetric absorption of DES was $0.0749 \mathrm{~g} \mathrm{CO}_{2} / \mathrm{g}$ DES, which was much lower than $0.62 \mathrm{~g} \mathrm{CO}_{2} / \mathrm{g}$ DES in the $30 \mathrm{wt} \% \mathrm{MEA}$ aqueous solution. Moreover, high-performance liquid chromatography (HPLC) analysis results showed that only $10 \%$ of amine reacted with $\mathrm{CO}_{2}$ while for the aqueous solution of $\mathrm{MEA}$, all of amine reacted with $\mathrm{CO}_{2}$. This means that the strong intermolecular hydrogen bonding was formed between $\mathrm{Cl}$ anions and MEA, which may hinder MEA from reacting with $\mathrm{CO}_{2}$.

Sarmad et al. [63] synthesized 35 DESs, in order to understand how HBD, HBA and other factors affect the properties of DESs at $298.15 \mathrm{~K}$ and pressures of up to $2 \mathrm{MPa}$, as shown in Table 3. For all DESs, the solubility increased with the increase of pressure, as is typically expected for the physical solubility of gases in liquids, i.e., the $\mathrm{CO}_{2}$ solubility is proportional to its partial pressure. The effect of different types of HBD with hydroxyl group or carboxylic group on the $\mathrm{CO}_{2}$ solubility was ordered as: [TEMA]Cl:EG > [TEMA]Cl:Ac $>$ [TEMA]Cl:LV > [TEMA]Cl:LA > [TEMA]Cl:GLY at the molar ratio of 1:2. The different types of HBA also had effect on the $\mathrm{CO}_{2}$ solubility. The $\mathrm{CO}_{2}$ solubilities in TPAC:MEA, TBAB:MEA and ChCl:MEA DESs under 298.15 $\mathrm{K}$ and $2 \mathrm{MPa}$ of $\mathrm{CO}_{2}$ were 3.525, 3.009 and $3.584 \mathrm{~mol} \mathrm{CO}_{2} / \mathrm{kg}$ DESs, respectively, and they followed the trend: TBAB:MEA > 
TPAC:MEA > ChCl:MEA. Additionally, increasing the alkyl chain length of HBA or HBD could lead to an increase of $\mathrm{CO}_{2}$ solubility. For example, the solubilities of $\mathrm{CO}_{2}$ in TEAC:AC DES (1:2) and TBAC:AC DES (1:2) were 1.177 and $1.411 \mathrm{~mol} \mathrm{CO}_{2} / \mathrm{kg}$ DESs, which increased as the alkyl chain length increased from ethyl to butyl. By increasing the alkyl chain length from acetic acid (AC) to octanoic acid (OCT) in TEAC:AC DES and TEAC:OCT DES, the solubility of $\mathrm{CO}_{2}$ increased from 1.230 to $1.390 \mathrm{~mol} \mathrm{CO}_{2} / \mathrm{kg}$ DESs. It is plausible that the length of the alkyl chain had a significant effect on the free volume within the DESs.

Zubeir et al. [64] investigated the $\mathrm{CO}_{2}$ solubility and Henry's constants in six hydrophobic DESs, which were prepared by combining decanoic acid (DecA) with five quaternary ammonium salts. The results show that the effect of the halide anions chloride and bromide of the quaternary ammonium salts on the $\mathrm{CO}_{2}$ solubility is negligible. The effect of alkyl chain length is consistent with the research by Sarmad [60]. Among the DESs, TBAC:DecA DES (1:2) shows the highest $\mathrm{CO}_{2}$ solubility of $1.52 \mathrm{~mol} \mathrm{CO}_{2} / \mathrm{kg}$ DESs at 298.15 $\mathrm{K}$ and $1990 \mathrm{kPa}$.

Table 3. $\mathrm{CO}_{2}$ solubility and Henry's constant in physical-based DESs.

\begin{tabular}{|c|c|c|c|c|c|c|}
\hline DESs & Molar Ratio & $T / K$ & $\mathrm{P} / \mathrm{kPa}$ & $\begin{array}{l}\mathrm{CO}_{2} \text { Solubil- } \\
\text { ity }(\mathrm{mol} / \mathrm{kg})\end{array}$ & $\begin{array}{c}\text { Henry's } \\
\text { Constant(MPa) }\end{array}$ & Ref. \\
\hline BHDE:AC & $1: 2$ & 298.15 & $210-2026$ & $0.064-0.84$ & & [63] \\
\hline BHDE:LA & $1: 2$ & 298.15 & 283-2086 & $0.016-0.50$ & & [63] \\
\hline BTEA:AC & $1: 2$ & 298.15 & $325-2054$ & $0.13-0.97$ & & [63] \\
\hline BTMA:AC & $1: 2$ & 298.15 & 219-2037 & $0.078-1.45$ & & [63] \\
\hline BTMA:GLY & $1: 2$ & 298.15 & 394-2026 & $0.037-0.26$ & & [63] \\
\hline [BTPP]Br:EG & $1: 12$ & 298.15 & 1000 & 0.6 & & [62] \\
\hline [BTPP]Cl:GLY & $1: 12$ & 298.15 & 1000 & 0.47 & & [62] \\
\hline ChCl:MEA & $1: 7$ & 298.15 & $182-2035$ & $0.78-3.58$ & & [63] \\
\hline Gua:MEA & $1: 2$ & 298.15 & $226-2025$ & $0.31-1.66$ & & [63] \\
\hline MTPP:1,2-Pro & $1: 4$ & 298.15 & $220-2026$ & $0.022-0.55$ & & [63] \\
\hline MTPP:AC & $1: 4$ & 298.15 & 173-2014 & $0.073-3.02$ & & [63] \\
\hline MTPP:EG & $1: 3$ & 298.15 & $192-2018$ & $0.045-0.35$ & & [63] \\
\hline MTPP:GLY & $1: 4$ & 298.15 & 161-2026 & $0.009-0.29$ & & [63] \\
\hline MTPP:LV & $1: 3$ & 298.15 & 301-2068 & $0.024-0.69$ & & [63] \\
\hline MTPP:MEA & $1: 6$ & 298.15 & 1000 & 1.63 & & [62] \\
\hline MTPP:MEA & $1: 7$ & 298.15 & 1000 & 1.46 & & [62] \\
\hline MTPP:MEA & $1: 8$ & 298.15 & 1000 & 1.44 & & [62] \\
\hline TBAC:DecA & $1: 2$ & $298.15-323.15$ & 90-1990 & $0.042-1.52$ & $7.55-10.71$ & [64] \\
\hline$\left[\mathrm{N}_{8881}\right] \mathrm{Br}: \mathrm{Dec} \mathrm{A}$ & $1: 2$ & $298.15-323.15$ & 90-1990 & $0.041-1.31$ & $7.15-9.43$ & [64] \\
\hline$\left[\mathrm{N}_{8881}\right] \mathrm{Cl}:$ DecA & $1: 2$ & 298.15-308.15 & 90-1990 & $0.045-1.35$ & $7.18-8.27$ & [64] \\
\hline$\left[\mathrm{N}_{8888}\right] \mathrm{Br}: \mathrm{DecA}$ & $1: 2$ & $298.15-323.15$ & 90-1990 & $0.039-1.33$ & $6.26-8.49$ & [64] \\
\hline$\left[\mathrm{N}_{8888}\right] \mathrm{Cl}: \mathrm{Dec} \mathrm{A}$ & $1: 1.5$ & 298.15-323.15 & 90-1990 & $0.041-1.41$ & $5.90-7.70$ & [64] \\
\hline$\left[\mathrm{N}_{8888}\right] \mathrm{Cl}: \mathrm{Dec} \mathrm{A}$ & $1: 2$ & 298.15-323.15 & 90-1990 & $0.042-1.41$ & $6.17-8.42$ & [64] \\
\hline TBAB:AC & $1: 2$ & 298.15 & 388-2011 & $0.14-1.13$ & & [63] \\
\hline TBAB:DEA & $1: 6$ & 298.15 & 1000 & 0.85 & & [62] \\
\hline TBAB:MEA & $1: 6$ & 298.15 & 1000 & 1.34 & & [62] \\
\hline TBAB:MEA & $1: 6$ & 298.15 & 351-2021 & $0.44-2.78$ & & [63] \\
\hline TBAB:MEA & $1: 7$ & 298.15 & $381-2040$ & $0.53-3.01$ & & [63] \\
\hline TBAB:TEA & $1: 3$ & 298.15 & 1000 & 0.47 & & [62] \\
\hline TBAC:AC & $1: 2$ & 298.15 & $348-2002$ & $0.18-1.41$ & & [63] \\
\hline TEAC:AC & $1: 2$ & 298.15 & $281-2018$ & $0.14-1.18$ & & [63] \\
\hline TEAC:AC & $1: 3$ & 298.15 & 397-2016 & $0.13-1.23$ & & [63] \\
\hline TEAC:OCT & $1: 3$ & 298.15 & 353-2018 & $0.16-1.39$ & & [63] \\
\hline TEMA:AC & $1: 2$ & 298.15 & 198-1837 & $0.081-1.18$ & & [63] \\
\hline TEMA:EG & $1: 2$ & 298.15 & $138-1345$ & $0.062-0.63$ & & [63] \\
\hline TEMA:GLY & $1: 2$ & 298.15 & 150-1648 & $0.017-0.43$ & & [63] \\
\hline TEMA:LA & $1: 2$ & 298.15 & $143-1863$ & $0.047-0.53$ & & [63] \\
\hline TEMA:LV & $1: 2$ & 298.15 & $136-1617$ & $0.057-0.61$ & & [63] \\
\hline TMAC:AC & $1: 4$ & 298.15 & 294-2096 & $0.12-1.56$ & & [63] \\
\hline TPAC:AC & $1: 6$ & 298.15 & 350-2030 & $0.25-1.72$ & & [63] \\
\hline TPAC:MEA & $1: 4$ & 298.15 & 481-2009 & $0.34-1.43$ & & [63] \\
\hline TPAC:MEA & $1: 7$ & 298.15 & 357-2019 & $1.71-3.53$ & & [63] \\
\hline
\end{tabular}

\section{Functionalized DESs for $\mathrm{CO}_{2}$ Capture}

\subsection{Amino-Based Functionalized DESs}

Amines are commonly used for the chemical absorption of $\mathrm{CO}_{2}$. Generally, two equivalents of amine can react with one equivalent of $\mathrm{CO}_{2}$ to form one equivalent of carbamate under anhydrous conditions, whereas an increase in viscosity is usually accompanied by the absorption process. MEA aqueous solution is widely used in industry for $\mathrm{CO}_{2}$ absorption. However, the solvent degradation and evaporation, corrosive to equipment limited the application of MEA. Zhang et al. [65] synthesized several BmimCl-based DESs 
with MEA as HBD. The $\mathrm{CO}_{2}$ uptake of BmimCl:MEA increased from $8.4 \%$ to $21.4 \%$ with the increase of the molar ratio of MEA from 1:1 to $1: 4$ at $298.15 \mathrm{~K}$ and $101 \mathrm{kPa}$, which was much higher than ChCl:MEA DES (1:6) (7.49\%) at 298.15 K and $1 \mathrm{MPa}$. The different performance of $\mathrm{ChCl}: \mathrm{MEA}$ and BmimCl:MEA can be attributed to the ability of cations to form hydrogen bonding with $\mathrm{Cl}^{-}$. According to the results of ${ }^{1} \mathrm{H} \mathrm{NMR}$, the $\mathrm{C} 2$ hydrogen in the DESs shifted to downfield as the composition changed with the addition of MEA, which implied that both of them formed hydrogen bonds with HBA as hydrogen bond donors. The acidic C2 hydrogen of imidazolium can formed a strong localized and highly directional hydrogen bond, which weakens the hydrogen bond between $\mathrm{MEA}$ and $\mathrm{Cl}^{-}$, resulting in an increase in absorption capacity.

Choi et al. [66] synthesized four dual amino-functionalized DESs by reacting various amino compounds, such as MEA, TEA, UE, TAA, ethylendiamine (EDA) with $\mathrm{HCl}$, and then mixed with EDA. The $\mathrm{CO}_{2}$ uptake capacity was ordered as: MEAC:EDA > TEAC:EDA > UEC:EDA > TAAC:EDA. The gravimetric uptake of MEAC:EDA DES with a molar ratio of $1: 3$ is $31.5 \mathrm{wt} \%$ correspond to $0.502 \mathrm{~mol} \mathrm{CO}_{2} / \mathrm{mol} \mathrm{DES} \mathrm{for} 3 \mathrm{~h}$, while the viscosity increased sharply from $21.6 \mathrm{mPa} \cdot \mathrm{s}$ to $3995 \mathrm{mPa} \cdot \mathrm{s}$ after $2.5 \mathrm{~min}$ of $\mathrm{CO}_{2}$ absorption. Excessive viscosity hindered the mass transfer process of $\mathrm{CO}_{2}$ in DES and is not conducive to the progress of absorption. To facilitate atmospheric regeneration and avoid high viscosity, MEAC:EDA DES (1:3) was diluted to be $30 \mathrm{wt} \%$ in EG. The $\mathrm{CO}_{2}$ desorption was achieved by heating the solution at $373.15 \mathrm{~K}$ for $2.5 \mathrm{~h}$. After that Shukla et al. [67] studied different types of polyamines and alcohol amines DESs formed between HBAs such as MEAC, HmimCl and TBAB and HBDs such as EDA, diethylenetriamine (DETA), tetraethylenepentamine (TEPA), pentaethylenehexamine (PEHA), 3-amino-1-propanol (AP) and aminomethoxypropanol (AMP). The results showed that the increase of the number of secondary amines in the molecule can hardly help to increase the mole absorption capacity of DES, but it will significantly reduce the mass absorption of DES, as shown in Table 4. For example, the $\mathrm{CO}_{2}$ uptakes by four MEA-based DESs could be ordered as MEAC:EDA $(39.0 \mathrm{wt} \%)>$ MEAC:DETA $(25.5 \mathrm{wt} \%)>$ MEAC:TEPA $(16.6 \mathrm{wt} \%)>$ MEAC:PEHA $(12.7$ $\mathrm{wt} \%$ ), corresponding to $0.57,0.57,0.63,0.59 \mathrm{~mol} \mathrm{CO}_{2} / \mathrm{mol} \mathrm{DES}$, respectively,. The effect of HBAs at a 1:4 molar ratio are following the order MEAC:AP > HmimCl:AP > TBAB:AP > TBAB:AMP. The $\mathrm{CO}_{2}$ absorption capacities of TBAB:AP DES (1:4) and TBAB:AMP DES (1:4) were 0.51 and $0.38 \mathrm{~mol} \mathrm{CO}_{2} / \mathrm{mol} \mathrm{DES}$, respectively, which implies that steric hindrance cannot improve the absorption capacity of MEA-based DESs.

Wu et al. [68] Designed a new class of functionalized DESs based on ammonium salts obtained from triethylenetetramine (TETA) and $\mathrm{HCl}$ at different molar ratios as HBA and EG and diethylene glycol (DG) as HBD. The results demonstrated that three aminos in [TETA]Cl can be activated by EG or DG. For example, the $\mathrm{CO}_{2}$ absorption capacities in [TETA] Cl and EG are $0.625 \mathrm{~mol} \mathrm{CO} / \mathrm{mol}[\mathrm{TETA}] \mathrm{Cl}$ and $0.0132 \mathrm{~mol} \mathrm{CO} / \mathrm{mol}$ EG at $313.15 \mathrm{~K}, 101 \mathrm{kPa}$, while the mole absorption capacity of [TETA]Cl:EG DES (1:3) was $1.465 \mathrm{~mol} \mathrm{CO}_{2} / \mathrm{mol}$ [TETA] Cl, corresponding to $0.175 \mathrm{~g} \mathrm{CO}_{2} / \mathrm{g}$ DES at the same condition. The effect of chloride ion was also studied and the result showed that $\mathrm{CO}_{2}$ absorption capacity decreased with the increase of the number of chloride ion. For instance, $\mathrm{CO}_{2}$ absorption capacity is $1.456 \mathrm{~mol} \mathrm{CO}_{2} / \mathrm{mol}$ [TETA]Cl for [TETA]Cl:EG DES, 0.986 $\mathrm{mol} \mathrm{CO} / \mathrm{mol}$ [TETA] $\mathrm{Cl}_{2}$ for [TETA] $\mathrm{Cl}_{2}: \mathrm{EG} \mathrm{DES}$, and $0.6 \mathrm{~mol} \mathrm{CO}_{2} / \mathrm{mol}^{2} \mathrm{TETA}_{\mathrm{Cl}}$ for [TETA] $\mathrm{Cl}_{3}$ :EG DES. As we know, there is always an amount of water in flue gas which can be absorbed by DESs during the absorption process. Although water content has a slight effect on absorptive capacity, it may increase the energy cost during the desorption process. Wu et al. [69] synthesized a new kind of hydrophobic functionalized DES formed by polyamine hydrochloride and thymol, which is hydrophobic before and after $\mathrm{CO}_{2}$ absorption. The absorption capacity of [TETA]Cl:thymol DES (1:3) was $0.09 \mathrm{~g} \mathrm{CO}_{2} / \mathrm{g}$ DES at $313.15 \mathrm{~K}$ and ambient pressure, corresponding to $1.298 \mathrm{~mol} \mathrm{CO}_{2} / \mathrm{mol} \mathrm{DES}$, which indicated that thymol could not enhance the capacity of $\mathrm{CO}_{2}$ in DESs.

Li et al. [70] synthesized a series of DESs based on ethanolamine and quaternary ammonium salt. From the results, the gravimetric absorption capacities vary with the length 
of the alkyl chain of the quaternary ammonium salt as follows: $\mathrm{ChCl} \approx \mathrm{TMAC}>\mathrm{TEAC}>$ TEAB $>$ TBAC $>$ TBAB. The effect of alcohol amine HBD with different numbers of substituents on absorption was ordered as: MEA $>$ DEA $>$ MDEA $>$ TEA. ChCl:MEA DES (1:5) exhibited the best performance with the capacities of $0.2523 \mathrm{~g} \mathrm{CO}_{2} / \mathrm{g}$ DESs. Considering the cost and absorptive capacity, there is an optimal molar ratio of 1:5. The desorption experiment requires higher temperatures $(373.15-413.15 \mathrm{~K})$ and longer time $(5 \sim 6 \mathrm{~h})$ due to high viscosity and strong interaction between $\mathrm{DES}$ and $\mathrm{CO}_{2}$.

\subsection{Azole-Based Functionalized DESs}

Azole-based functionalized DESs are another kind of functionalized DESs used for the capture of $\mathrm{CO}_{2}$. Yang et al. [71] reported a new class of DESs made up of solid azole-based

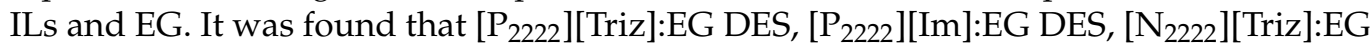
DES and [ $\left.\mathrm{N}_{2222}\right][\mathrm{Im}]$ :EG DES had almost the same amounts of absorption. The $\mathrm{CO}_{2}$ absorption capacities of four different DESs with a molar ratio of $1: 2$ were $0.118,0.118$, $0.125,0.129 \mathrm{~g} \mathrm{CO}_{2} / \mathrm{g}$ DES at $298.15 \mathrm{~K}$ and $101 \mathrm{kPa}$, corresponding to $0.91,0.91,0.92$ and 0.94 $\mathrm{mol} \mathrm{CO}_{2} / \mathrm{mol}$ DES, which implied the absorption mechanism of azolide anions in DES is different from ILs [72,73]. The results of NMR and FTIR indicated that $\mathrm{CO}_{2}$ did not directly interact with the azolide anions to form a carbamate species but reacted with EG that was deprotonated by [Triz] anion to form carbonate. $\mathrm{CO}_{2}$ absorbed by the solvent can be completely released at $343.15 \mathrm{~K}$ under $\mathrm{N}_{2}$ flow. Gurkan et al. [74] reported a new reactive DES formed by 1-ethyl-3-methylimidazolium 2-cyanopyrrolide ([Emim][2-CNpyr]) and EG. [Emim][2-CNpyr]:EG DES (1:2) formed is thermally stable and has low viscosity DES, which shows absorption capacities of 10.3 and $11.4 \mathrm{wt} \%$ at $0.005 \mathrm{bar}$ and $1 \mathrm{bar}$ of $\mathrm{CO}_{2}$, respectively, at $298.15 \mathrm{~K}$. The absorbed $\mathrm{CO}_{2}$ at $298.15 \mathrm{~K}$ can easily be released under $\mathrm{N}_{2}$ at $313.15 \mathrm{~K}$. Multiple species were found in the product of $\mathrm{CO}_{2}$ absorption. On the basis of NMR and FTIR analysis, they proposed four possible routes, as shown in Figure 5. Route 1 is the complexation of $\mathrm{CO}_{2}$ with the pyrrolide anion that forms carbamate $(\mathrm{N}-\mathrm{COO})$. Route 2 is the deprotonation of the imidazolium cation by the anion that forms a carbene zwitterion, which then binds with $\mathrm{CO}_{2}$ to form carboxylate $(-\mathrm{C}-\mathrm{COO})$. Route 3 is the protonation of the anion by EG, resulting in deprotonated EG that subsequently reacts with $\mathrm{CO}_{2}$ to form carbonate $(-\mathrm{O}-\mathrm{COO})$. In the presence of water, bicarbonate $(\mathrm{HO}-\mathrm{COO})$ also forms via Route 4.

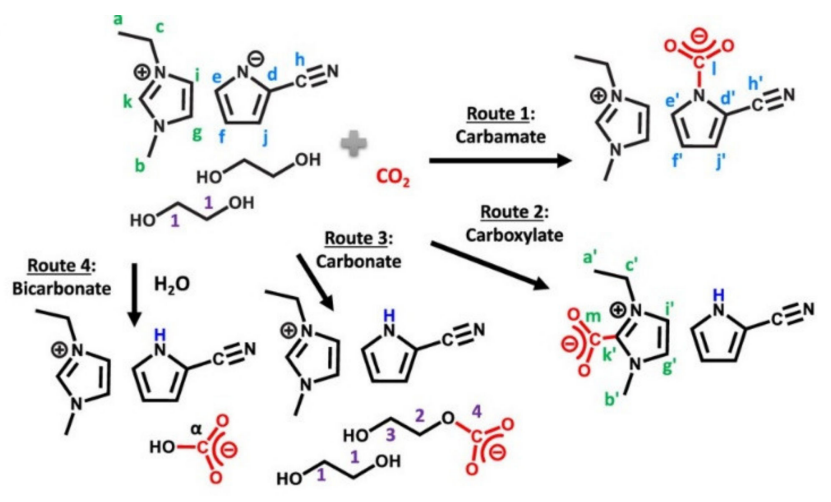

Figure 5. Proposed reaction network with NMR labeling of the reactants and $\mathrm{CO}_{2}$ bound products. (Reprinted with permission from Ref. [74]. Copyright (2021) American Chemical Society).

\subsection{Super Base Functionalized DESs}

Another covalent strategy for reversible $\mathrm{CO}_{2}$ capture is to combine organic compounds containing alcohol functionalized groups with superbases. Superbases (SBs), neutral organic bases with proton affinities so high that their protonated conjugate acids $\left(\mathrm{BH}^{+}\right)$cannot be deprotonated by the hydroxide ion, play a key role as proton acceptors in the preparation of supported protic ionic liquids (PILs) with exceptional thermal stability [75,76]. Due to the many similarities between DESs and ILs, Baker et al. [77] for the first time added super base 
into ChCl:Gly DES to form ternary DESs. The structures of DES components and various superbases are shown in Figure 6A. The result demonstrated the addition of super base enabled ChCl:Gly DES to chemically absorb $\mathrm{CO}_{2}$ by deprotonating the hydroxyl group in choline chloride or glycerol to form the negative oxygen which acted as chemical absorption site to react with $\mathrm{CO}_{2}$ and generate carbonate under ambient conditions (Figure $6 \mathrm{~B}$ ). The effect of three different types of $\mathrm{SBs}$ on $\mathrm{CO}_{2}$ absorption capacity was investigated under ambient conditions, and obtained the corresponding absorption capacity of $0.103,0.100,0.035 \mathrm{~g} \mathrm{CO}_{2} / \mathrm{g}$ DES for ChCl:Gly:1,5-diazabicyclo[4.3.0]-non-5-ene (DBN) DES (1:2:6), ChCl:Gly:7-methyl1,5,7-triazabicyclo[4.4.0]dec-5-ene (MTBD) DES (1:2:6), ChCl:Gly:1,8-diazabicyclo[5.4.0]undec7-ene (DBU) DES (1:2:6), respectively. DBN leaded to optimal $\mathrm{CO}_{2}$ capture, due to its higher basicity and less steric hindrance. As a result of chemical absorption, the viscosity of all ternary DES systems increased with the increase of absorbed amount. After absorption, ChCl:Gly:DBN DES (1:2:6) showed a viscosity ranged from 5450 to $34,613 \mathrm{mPa} \cdot \mathrm{s}$ that is 1 to 2 orders of magnitude higher than traditional ILs and separated into two phases. Such a viscosity increase negatively affects mass transfer and capture kinetics, hindering further $\mathrm{CO}_{2}$ capture. However, the absorbed $\mathrm{CO}_{2}$ could be released completely within $35 \mathrm{~min}$ at $333.15 \mathrm{~K}$, while a noticeable capacity decreased can be observed after three cycles during the cycling experiments due to slight evaporative losses of the superbase component.

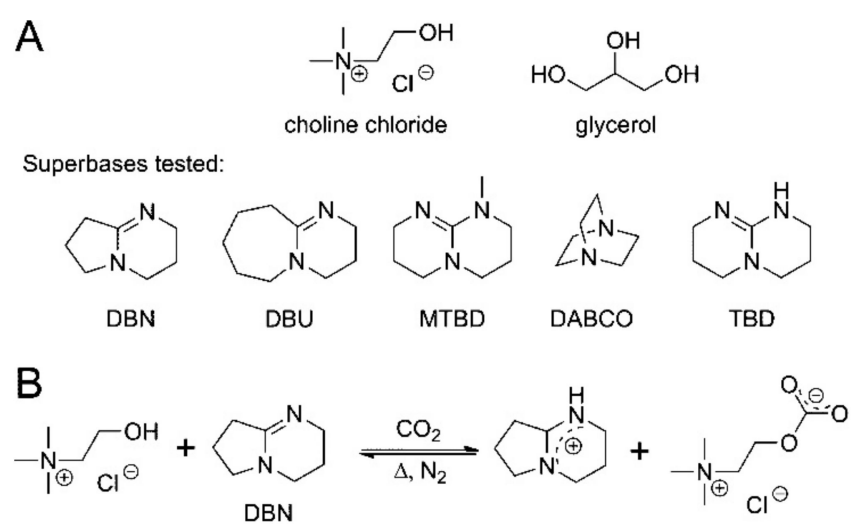

Figure 6. (A) Structures of the DES components: choline chloride, glycerol, and various superbases. (B) Proposed reaction scheme for superbase-promoted $\mathrm{CO}_{2}$ capture using a task-specific DES. In this scheme, choline chloride and the superbase DBN are shown for illustration; however, a similar reaction is believed to be operative for the other superbases as well as for $\mathrm{CO}_{2}$ binding to the multiple alcohol functionalities of glycerol (Reprinted with permission from Ref. [77]. Copyright (2014) American Chemical Society).

Afterward, Zhang et al. [78] paired DBN with EU, 1,3-dimethylurea (DMU), and dimethylolurea (DMLU) to synthesize a series of novel superbase/acylamido-based DESs with low viscosity. Most of these DESs with the viscosity no more than $12 \mathrm{mPa} \cdot \mathrm{s}$ exhibited excellent gravimetric absorption capacity. For example, the $\mathrm{CO}_{2}$ gravimetric absorption capacities of DBN:EU DES (2:1), DBN:DMU DES (2:1), and DBN:DMLU DES (2:1) were $23.02,17.34$, and $4.27 \mathrm{wt} \%$, respectively. Even though it is inevitable that the viscosity increases with the increase of the amount of $\mathrm{CO}_{2}$ absorbed. Owing to the coaction of reaction dynamics and reaction thermodynamics, the absorption capacity and the rate of the DBN:EU DES (2:1) increased with the increase in temperature from $298.15 \mathrm{~K}$ to $318.15 \mathrm{~K}$, after that the $\mathrm{CO}_{2}$ uptake decreased from $318.15 \mathrm{~K}$ to $338.15 \mathrm{~K}$. So that it can be regenerated at $353.15 \mathrm{~K}$, with the desorption ratio in the range of $86-87 \%$. The results of NMR and FTIR indicated that DBN deprotonated the $-\mathrm{NH}$ in EU, and a new $\mathrm{N}-\mathrm{C}$ bond was formed after capturing $\mathrm{CO}_{2}$. Then they prepared ternary DESs by mixing DBN with BmimCl:Im for $\mathrm{CO}_{2}$ absorption [79]. The experimental results of DBN:BmimCl:Im DES (1:1:1) and DBNH:Im DES (1:1) indicated that these two absorbents exhibited different absorption behavior. For instance, the viscosity of [DBNH] $[\mathrm{Im}]$ increased rapidly with 
$\mathrm{CO}_{2}$ absorption and became solid after absorption, while DBN:BmimCl:Im DESs with different molar ratios were all clear liquids after absorbing $\mathrm{CO}_{2}$, and the time consumption of reaching the adsorption balance was much shorter than that of [DBNH][Im]. The $\mathrm{CO}_{2}$ uptake of DBN:BmimCl:Im DES (1:2:1), exhibited the highest absorption capacity of 1.07 mol CO $2 / \mathrm{mol} \mathrm{DES}$. On the basis of NMR and FTIR analysis, $\mathrm{CO}_{2}$ was reacted with nitrogen atom on imidazole which was deprotonated by DBN to form $[\mathrm{Im}-\mathrm{COO}]^{-}$and then a strong intermolecular hydrogen bond was formed between $\left[\mathrm{Im}-\mathrm{COO}^{-}\right]$and $[\mathrm{DBNH}]^{+}$in DBNH:Im DES. For ternary DESs, $\mathrm{CO}_{2}$ was reacted with $\mathrm{C} 2$ hydrogen on the $[\mathrm{Bmim}]^{+}$and then $\left[\mathrm{Bmim}^{+}-\mathrm{COO}^{-}\right]$formed a hydrogen bond with $[\mathrm{DBNH}]^{+}$.

Zeng et al. [80] prepared three superbase ILs, [HDBU][Im], [HDBU][Ind], and [HDBU][Triz] and further combined with EG to from IL-based DESs for an efficient and reversible capture of $\mathrm{CO}_{2}$. The amount of $\mathrm{CO}_{2}$ absorbed by IL-based DESs followed the order of [HDBU][Im]:EG (0.141 $\mathrm{g} \mathrm{CO}_{2} / \mathrm{g}$ DES) > [HDBU][Ind]:EG (0.117 $\mathrm{g} \mathrm{CO}_{2} / \mathrm{g}$ DES) > [HDBU][Triz]:EG (0.108 g $\mathrm{CO}_{2} / \mathrm{g}$ DES) with a mass ratio of $7: 3$ at $313.15 \mathrm{~K}$ and $100 \mathrm{kPa}$, which is consistent with the basic order of DESs. The viscosities of all three DESs after absorbing $\mathrm{CO}_{2}$ increase slightly, while the three pure ILs after $\mathrm{CO}_{2}$ absorption become a gelatinous state. The absorbed $\mathrm{CO}_{2}$ could be completely released under $343.15 \mathrm{~K}$ with $\mathrm{N}_{2}$ purging, and $\mathrm{CO}_{2}$ absorption capacity remained nearly unchanged. Two kinds of possible mechanism of [HDBU][Im]:EG DES for $\mathrm{CO}_{2}$ absorption were proposed. One pathway was that the $\mathrm{H}$ atom on EG transfers to the electronegative $\mathrm{N}$ of the IL to obtain the final product of carbonate, and the other was that IL reacts with $\mathrm{CO}_{2}$ directly to generate carbonate. Therefore, the process of IL-based DES for $\mathrm{CO}_{2}$ absorption was proved to be the synergistic interaction between $\mathrm{EG}$, IL, and $\mathrm{CO}_{2}$, resulting in the mixed product of carbamate and carbonate.

Table 4. $\mathrm{CO}_{2}$ solubility in functionalized DESs.

\begin{tabular}{|c|c|c|c|c|c|c|}
\hline DESs & Molar Ratio & $T / K$ & $\begin{array}{c}\text { Capacity at } 101 \\
\mathrm{kPa} / \mathbf{w t} \%\end{array}$ & $\begin{array}{l}\text { Viscosity of Pure } \\
\text { DESs/mPa.s }\end{array}$ & $\begin{array}{c}\text { Viscosity of DESs } \\
\text { after } \mathrm{CO}_{2} \\
\text { Uptake/mPa.s }\end{array}$ & Ref. \\
\hline BmimCl: MEA & $1: 1$ & 298 & 8.4 & & & [65] \\
\hline BmimCl: MEA & $1: 2$ & 298 & 17.9 & & & [65] \\
\hline BmimCl: MEA & $1: 4$ & 298 & 21.4 & & & [65] \\
\hline ChCl:Gly:DBN & $1: 2: 3$ & $\mathrm{RT}$ & 9.6 & & & [77] \\
\hline ChCl:Gly:DBN & $1: 2: 6$ & RT & 10.3 & & & [77] \\
\hline ChCl:Gly:DBN & $1: 2: 7$ & RT & 10.5 & & & [77] \\
\hline ChCl:Gly:DBN & $1: 2: 8$ & $\mathrm{RT}$ & 10.3 & & & [77] \\
\hline ChCl:Gly:DBN & $1: 3: 10$ & RT & 10.4 & & & [77] \\
\hline ChCl:Gly:DBU & $1: 2: 6$ & $\mathrm{RT}$ & 3.55 & & & [77] \\
\hline ChCl:Gly:MTBD & $1: 2: 6$ & RT & 10 & & & [77] \\
\hline ChCl:MEA & $1: 5$ & 303.15 & 25.23 & & & [70] \\
\hline DBN:BmimCl:Im & $1: 1: 1$ & 298.15 & $(1.02)^{1}$ & & & [79] \\
\hline DBN:BmimCl:Im & $1: 1: 2$ & 298.15 & $(0.97)^{1}$ & & & [79] \\
\hline DBN:BmimCl:Im & $1: 2: 1$ & 298.15 & $(1.07)^{1}$ & & & [79] \\
\hline DBN:DMLU & $2: 1$ & 318.15 & $4.27 ; 2.47^{2}$ & $>1000$ & $>10000$ & [78] \\
\hline DBN:DMU & $2: 1$ & 318.15 & $17.34 ; 16.8^{2}$ & $2.52 \pm 0.05$ & $>3000$ & [78] \\
\hline DBN:EU & $2: 1$ & 318.15 & $23.02 ; 19.98^{2}$ & $11.85 \pm 0.10$ & $>3000$ & [78] \\
\hline
\end{tabular}


Table 4. Cont.

\begin{tabular}{|c|c|c|c|c|c|c|}
\hline DESs & Molar Ratio & $T / K$ & $\begin{array}{c}\text { Capacity at } 101 \\
\mathbf{k P a} / \mathbf{w t} \%\end{array}$ & $\begin{array}{c}\text { Viscosity of Pure } \\
\text { DESs/mPa.s }\end{array}$ & $\begin{array}{c}\text { Viscosity of DESs } \\
\text { after } \mathrm{CO}_{2} \\
\text { Uptake/mPa.s }\end{array}$ & Ref. \\
\hline DBN:EU & $3: 1$ & 318.15 & $19.31 ; 17.33^{2}$ & $7.56 \pm 0.03$ & & [78] \\
\hline $\begin{array}{c}\text { [Emim][2- } \\
\text { CNpyr]:EG }\end{array}$ & $1: 2$ & 298.15 & $11.4,10.3^{3}$ & & & [74] \\
\hline [HDBU][Im]:EG & $7: 3$ & 313.15 & 0.141 & & & [80] \\
\hline [HDBU][Ind]:EG & $7: 3$ & 313.15 & 0.117 & & & [80] \\
\hline [HDBU][Triz]:EG & $7: 3$ & 313.15 & 0.108 & & & [80] \\
\hline $\mathrm{HmimCl}: \mathrm{AP}$ & $1: 1$ & RT & $2.0(0.04)^{1}$ & 130.6 & & [67] \\
\hline HmimCl:AP & $1: 2$ & RT & $9.5(0.21)^{1}$ & 57 & & [67] \\
\hline HmimCl:AP & $1: 3$ & RT & $13.9(0.30)^{1}$ & 49.9 & & [67] \\
\hline $\mathrm{HmimCl}: \mathrm{AP}$ & $1: 4$ & RT & $19.4(0.37)^{1}$ & 39 & & [67] \\
\hline HmimCl:PEHA & $1: 4$ & RT & $8.4(0.4)^{1}$ & 213 & & [67] \\
\hline HmimCl:DETA & $1: 4$ & RT & $22.8(0.55)^{1}$ & 17.3 & & [67] \\
\hline $\mathrm{HmimCl}: \mathrm{EDA}$ & $1: 1$ & RT & $9.0(0.19)^{1}$ & 80 & & [67] \\
\hline HmimCl:EDA & $1: 2$ & RT & $25.0(0.45)^{1}$ & 14.1 & & [67] \\
\hline HmimCl:EDA & $1: 3$ & RT & $26.7(0.45)^{1}$ & 7.7 & & [67] \\
\hline HmimCl:EDA & $1: 4$ & RT & $30.8(0.50)^{1}$ & 5.8 & & [67] \\
\hline HmimCl:TEPA & $1: 4$ & RT & $9.9(0.39)^{1}$ & 100.5 & & {$[67]$} \\
\hline MEAC:AP & $1: 1$ & RT & $15.8(0.28)^{1}$ & 126.7 & & [67] \\
\hline MEAC:AP & $1: 2$ & RT & $21(0.37)^{1}$ & 67 & & [67] \\
\hline MEAC:AP & $1: 3$ & RT & $24.3(0.42)^{1}$ & 64 & & [67] \\
\hline MEAC:AP & $1: 4$ & RT & $26.3(0.46)^{1}$ & 55 & & [67] \\
\hline MEAC:DETA & $1: 4$ & RT & $25.5(0.57)^{1}$ & 19.2 & & [67] \\
\hline MEAC:EDA & $1: 1$ & RT & $23.5(0.38)^{1}$ & 128 & & [67] \\
\hline MEAC:EDA & $1: 2$ & $\mathrm{RT}$ & $30.9(0.47)^{1}$ & 17.3 & & [67] \\
\hline MEAC:EDA & $1: 3$ & RT & $36.5(0.54)^{1}$ & 9.6 & & [67] \\
\hline MEAC:EDA & $1: 3$ & 303.15 & 33.7 & 21.6 & 3995 & [66] \\
\hline MEAC:EDA & $1: 4$ & RT & $39.0(0.57)^{1}$ & 7 & & [67] \\
\hline MEAC:PEHA & $1: 4$ & RT & $12.7(0.59)^{1}$ & 222 & & [67] \\
\hline MEAC:TEPA & $1: 4$ & RT & $16.6(0.63)^{1}$ & 109.4 & & [67] \\
\hline$\left[\mathrm{N}_{2222}\right][\mathrm{Im}]: \mathrm{EG}$ & $1: 2$ & 298.15 & $12.9(0.94)^{1}$ & & & [71] \\
\hline$\left[\mathrm{N}_{2222}\right][$ Triz]:EG & $1: 2$ & 298.15 & $12.5(0.92)^{1}$ & & & [71] \\
\hline$\left[\mathrm{P}_{2222}\right][\mathrm{Im}]: \mathrm{EG}$ & $1: 2$ & 298.15 & $11.8(0.91)^{1}$ & & & [71] \\
\hline$\left[\mathrm{P}_{2222}\right][$ Triz]:EG & $1: 2$ & 298.15 & $11.8(0.91)^{1}$ & & & [71] \\
\hline TAEC:EDA & $1: 3$ & 303.15 & 14.6 & 30.7 & 748.8 & [66] \\
\hline TBAB:AMP & $1: 3$ & RT & $10.5(0.35)^{1}$ & 199.7 & & [67] \\
\hline TBAB:AMP & $1: 4$ & RT & $12.2(0.38)^{1}$ & 252.263 & & [67] \\
\hline TBAB:AP & $1: 2$ & RT & $11.1(0.43)^{1}$ & 243 & & [67] \\
\hline TBAB:AP & $1: 3$ & RT & $15.6(0.49)^{1}$ & 51.2 & & [67] \\
\hline TBAB:AP & $1: 4$ & RT & $18.1(0.51)^{1}$ & 38.4 & & [67] \\
\hline TEAC:EDA & $1: 3$ & 303.15 & 24.2 & 52.4 & 3343 & [66] \\
\hline [TETA]Cl:DG & $1: 2$ & 313.15 & 0.159 & & & [68] \\
\hline [TEPA]Cl:thymol & $1: 3$ & 313.15 & $0.088(1.355)^{1}$ & 295.7 & 16,800 & [69] \\
\hline [TETA]Cl:EG & $1: 3$ & 313.15 & 0.175 & & & [68] \\
\hline [TETA]Cl:thymol & $1: 3$ & 313.15 & $0.09(1.298)^{1}$ & 205.1 & 6770 & [69] \\
\hline UEC:EDA & $1: 3$ & 303.15 & 17.8 & 29.5 & 3011 & [66] \\
\hline
\end{tabular}

${ }^{1}$ Data in brackets are the molar fraction. ${ }^{2}$ The $\mathrm{CO}_{2}$ concentration was $14 \% .{ }^{3}$ The $\mathrm{CO}_{2}$ concentration was $0.5 \%$.

\section{Non-Functionalized DESs for NO Capture}

In 2011, Duan et al. [81] synthesized three kinds of DESs using CPL as HBD and tetrabutylamine halide as HBAs to absorbed NO. The solubility of $\mathrm{NO}$ with various halide anions displayed the following trend: $\mathrm{F}^{-}>\mathrm{Br}^{-}>\mathrm{Cl}^{-}$, which means that halogen anions play an important role in the absorption process. It can be seen that the solubility of $\mathrm{NO}$ in the DESs increased as the temperature increased from 308.15 to $363.15 \mathrm{~K}$ and molar ratio affected the absorption rate. The solubility of NO in CPL:TBAB DESs (4:1 and 6:1) 
increased sharply with an increase in temperature. The highest mole fraction solubility of $\mathrm{NO}$ was $0.170 \mathrm{~mol} \mathrm{NO} / \mathrm{mol}$ DES with a molar ratio of $4: 1$ at $353.15 \mathrm{~K}$. The results of ${ }^{1} \mathrm{H}$ NMR spectra showed that NO was physically absorbed by DESs. It is worth noting that the colorless TBAB:CPL DES changed to pale yellow after absorbing NO. It is well-known that the appearance of a yellowish to orange color in the sulfur dioxide solvates of halides and pseudohalides are assigned to a charge transfer interaction, where $\mathrm{SO}_{2}$ acts as an electron acceptor species $[82,83]$. It is reported that $\mathrm{NO}$ can also act as an electron acceptor $[84,85]$. Therefore, the color change of TBAB:CPL DES may be due to the charge transfer between $\mathrm{Br}^{-}$and NO.

\section{Functionalized DESs for NO Capture}

In recent years, considerable efforts have focused on the experimental and theoretical studies in the field of acidic gas separation and absorption by ILs. However, it was difficult for NO to form the hydrogen bonding with ILs, owing to its weak chemical polarity. Therefore, DESs, with chemical absorption capacity, are highly desirable. In 1960, Drago et al. [84] for the first time reported that $\mathrm{NO}$ could reacted with secondary amines to form the product $\mathrm{Et}_{2} \mathrm{NH}_{2}{ }^{+} \mathrm{Et}_{2} \mathrm{~N}_{2} \mathrm{O}_{2}{ }^{-}$. However, the mechanism of whether the nitric oxide molecule dimer added base or whether nitric oxide added base and then reacted with another nitric oxide molecule have not been clarified. Until 2008, Laali et al. [83] explored the kinetics and mechanism of the reaction between secondary amines and NO. The mechanism is interpreted in terms of competitive addition of amine to either $\mathrm{NO}$ or its dimer. The NO solubility with the scale of $\mathrm{mol} \mathrm{mol}^{-1}$ for the studied DESs are given in Table 5.

\section{Amino-Functionalized DES}

Tantai et al. [86,87] synthesized a series of DMU and 1,3-dimethylthiourea (1,3-DMTU)based DESs, paired with tetrabutylphosphine halides and tetrabutylamine halides, such as $\mathrm{P}_{4444} \mathrm{Cl}, \mathrm{P}_{4444} \mathrm{Br}, \mathrm{TBAC}$, and TBAB. The result showed that the DESs containing chlorine salts as HBAs performed much better absorption capacity than those containing bromine salts, which is consistent with previous reports, as shown in Figure 7a. Moreover, the NO absorption capacity increased with the increase of the molar ratio of 1,3-DMTU in the DESs (Figure 7b), which indicated that the primary amine of 1,3-DMTU is the main site for chemical absorption of NO. For example, the absorption capacity of $\mathrm{P}_{4444} \mathrm{Cl}$ :DMTU increased from 2.10 to $4.25 \mathrm{~mol} \mathrm{NO} / \mathrm{mol}$ DES at $303.15 \mathrm{~K}$ and $101.3 \mathrm{kPa}$, as the molar ratio increased from 1:1 to 3:1. Additionally, 1,3-DMTU exhibits better performance than DUM as HBA in absorption capacity. The solubility of $\mathrm{NO}$ in $\mathrm{P}_{4444} \mathrm{Cl}: 1,3-\mathrm{DMTU}$ DES (1:1) is $1.13 \mathrm{~mol} \mathrm{NO} / \mathrm{mol} \mathrm{DES}$ at $303.15 \mathrm{~K}$ and $101.3 \mathrm{kPa}$, which is much higher than $0.663 \mathrm{~mol}$ $\mathrm{NO} / \mathrm{mol}$ DES in $\mathrm{P}_{4444} \mathrm{Cl}$ :DMTU DES (1:1). The results can be interpreted as sulfur atom is more electronegative than oxygen atom, so more of the charge from nitrogen is transferred to sulfur atoms, resulting in a drop in the electron cloud density of a nitrogen atom. As a consequence, the amino groups on 1,3-DMTU are prone to deprotonated than the amino groups on DMU, which is more conducive to the progress of the reaction. Nevertheless, the desorption residue $\mathrm{P}_{4444} \mathrm{Cl}: 1,3-\mathrm{DMTU}$ DES (1:3) was about $1.3 \mathrm{~mol} \mathrm{NO} / \mathrm{mol} \mathrm{DES}$, while the absorbed NO by $\mathrm{P}_{4444} \mathrm{Br}$ : DMU DES (1:3) can be completely desorbed, due to the stronger interaction between $\mathrm{NO}$ and 1,3-DMTU. 


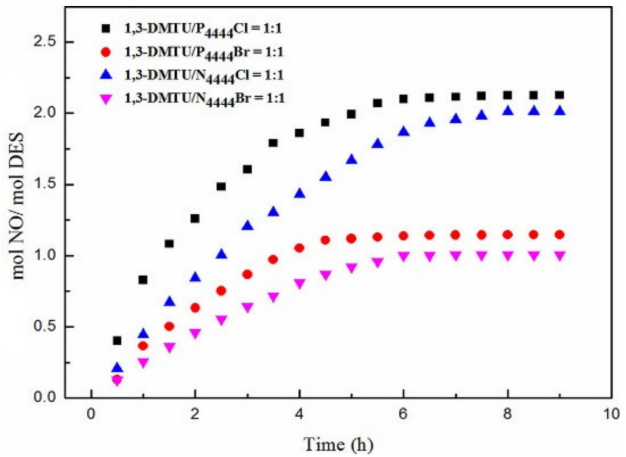

(a)

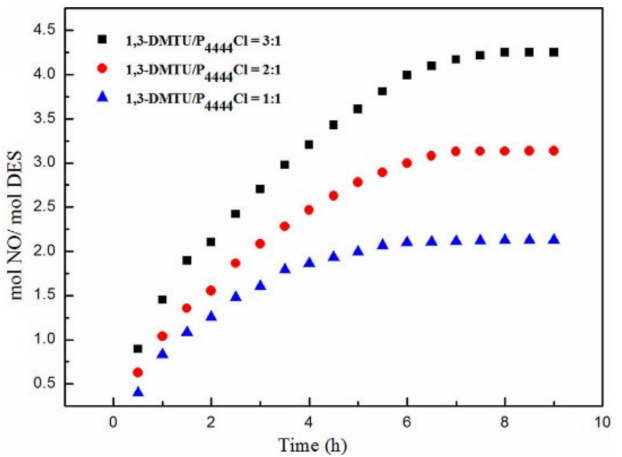

(b)

Figure 7. (a) NO absorption by DESs with different HBAs at $303.15 \mathrm{~K}$; (b) NO absorption by DESs with different molar ratios of 1,3-DMTU to $\mathrm{P}_{4444} \mathrm{Cl}$ at $303.15 \mathrm{~K}$ (Reprinted with permission from Ref. [87]. Copyright (2017) American Chemical Society).

Considering the effect of deprotonation on absorptive capacity, they chose azole-derived as HBDs paired with $\mathrm{P}_{4444} \mathrm{Cl}$ as $\mathrm{HBA}$ to synthesize DESs for further research [88]. The absorption capacity with different azole-derived HBDs was ordered as Tetz: $\mathrm{P}_{4444} \mathrm{Cl}>$ Triz: $\mathrm{P}_{4444} \mathrm{Cl}>$ Im: $\mathrm{P}_{4444} \mathrm{Cl}$, and the same trend was observed in ChCl-based DESs (Figure 8a). Please note that this order was opposite to the basic order of azole derivatives. As shown in Figure 8b, the effect of $\mathrm{NO}$ partial pressure on the $\mathrm{NO}$ absorption capacity of Tetz: $\mathrm{P}_{4444} \mathrm{Cl}$ was studied. Notably, under low partial pressures ranging from 2 to $12 \mathrm{kPa}$, the $\mathrm{NO}$ absorption capacities increased sharply from 0.39 to $1.01 \mathrm{~mol} \mathrm{NO} / \mathrm{mol} \mathrm{DES}$, which confirmed the efficient chemical absorption of NO under low partial pressures. After that it increased linearly to $2.10 \mathrm{~mol}$ $\mathrm{NO} / \mathrm{mol} \mathrm{DES}$ when the partial pressure of NO increased from 12 to $101 \mathrm{kPa}$ at $303.15 \mathrm{~K}$, which was a physical absorption process. The experiment corroborated that $\mathrm{Cl}^{-}$can significantly absorb NO through physical interaction. The highest absorption capacity of Tetz: $\mathrm{P}_{4444} \mathrm{Cl}$ is equivalent to that of 1,3-DMTU: $\mathrm{P}_{4444} \mathrm{Cl}$ under the same conditions. Although Tetz: $\mathrm{P}_{4444} \mathrm{Cl}$ possessed desirable reusability for $\mathrm{NO}$ absorption and could maintain high $\mathrm{NO}$ absorption after recycling five times. About $0.72 \mathrm{~mol} \mathrm{NO} / \mathrm{mol} \mathrm{DES}$ remained after desorption, indicating a desorption rate of nearly $66 \%$.

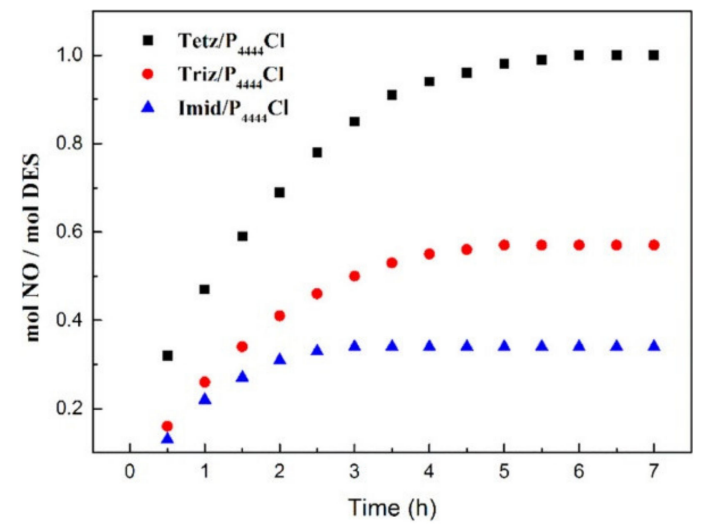

(a)

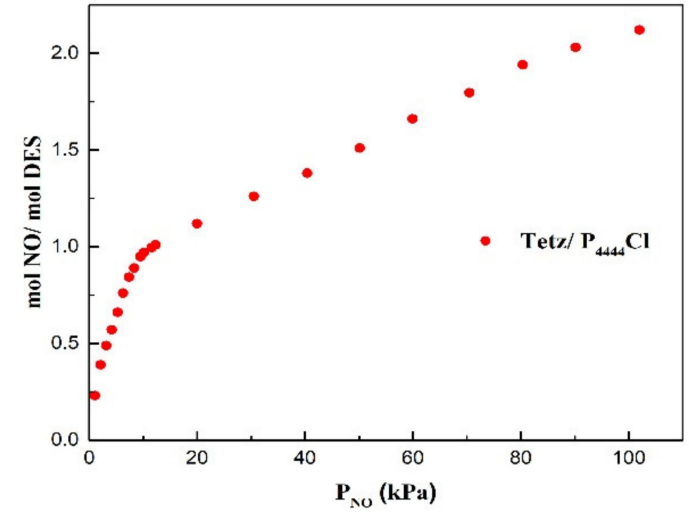

(b)

Figure 8. (a) NO absorption by $\mathrm{P}_{4444} \mathrm{Cl}$-based DESs at $343.15 \mathrm{~K}$ and $101.3 \mathrm{kPa}$; (b) Effect of $\mathrm{NO}$ partial pressure on the NO capture of Tetz $/ \mathrm{P}_{4444} \mathrm{Cl}$ DES at $303.15 \mathrm{~K}$ (Reprinted with permission from Ref. [88]. Copyright (2019) American Chemical Society).

However, the DESs mentioned above were only performed to capture pure NO. In the light of the reaction of NO with the primary amine of dipropylamine (DPA) to form dipropyldiazeniumdiolate [83], Wu et al. [89] synthesized a series of polyamine-based DES and successfully used them for the absorption of low concentrations. Triethylenetetramine 
chloride([TETA]Cl) and tetraethylenepentamine chloride ([TEPA]Cl) were chosen as HBAs and 1,3-propanediol (1,3-PDO), Gly, polyethylene glycol (PEG), and EG were chosen as HBDs. [TEPA]Cl:EG DES with 1:3 molar ratio exhibited the best performance with the capacity of $4.52 \mathrm{~mol} \mathrm{NO} / \mathrm{mol}$ DES $(0.33 \mathrm{~g} \mathrm{NO} / \mathrm{g}$ DES$)$ at $303 \mathrm{~K}$ and $101 \mathrm{kPa}$. It is worth noting that even though EG is not the main absorption component, increasing the molar ratio of EG can still increase the gravimetric absorption capacity, which demonstrated that EG can promote the absorption process enhancing the basicity of [TEPA]Cl though hydrogen bonding interactions.

Table 5. NO solubility in functionalized DESs.

\begin{tabular}{|c|c|c|c|c|c|c|c|}
\hline DESs & Molar Ratio & $T / \mathrm{K}$ & $\begin{array}{c}\text { Capacity at } \\
101 \mathrm{kPa} g \\
\text { NO/g DES }\end{array}$ & $\begin{array}{c}\text { Capacity at } \\
10 \mathrm{kPa} \text { mol } \\
\text { NO/mol } \\
\text { DES }\end{array}$ & $\begin{array}{c}\text { Viscosity of } \\
\text { Pure } \\
\text { DESs/mPa.s }\end{array}$ & $\begin{array}{c}\text { Viscosity of } \\
\text { DESs after } \\
\text { NO } \\
\text { Uptake/mPa·s }\end{array}$ & Ref. \\
\hline $\begin{array}{c}\text { [TEPA]Cl:1,3- } \\
\text { PDO }\end{array}$ & $1: 1$ & 303.15 & & $(3.25)^{1}$ & & & [89] \\
\hline [TEPA]Cl:EG & $1: 1$ & 303.15 & & $(3.10)^{1}$ & & & [89] \\
\hline [TEPA]Cl:EG & $1: 3$ & 303.15 & & $(4.52)^{1}$ & & & [89] \\
\hline [TEPA]Cl:Gy & $1: 1$ & 303.15 & & $(3.35)^{1}$ & & & [89] \\
\hline [TEPA]Cl:PEG & 1:1 & 303.15 & & $(3.45)^{1}$ & & & [89] \\
\hline [TETA]Cl:EG & $1: 1$ & 303.15 & & $(2.49)^{1}$ & & & [89] \\
\hline CPL:TBAB & $4: 1$ & 353.15 & $(0.17)^{1}$ & & & & [81] \\
\hline $\begin{array}{l}\text { TBAB:1,3- } \\
\text { DMTU }\end{array}$ & $1: 1$ & 303.15 & $(1.00)^{1}$ & & 1123 & & [87] \\
\hline TBAB:Tetz & $1: 1$ & 303.15 & $0.024(0.32)^{1}$ & & 279.15 & 26.32 & [88] \\
\hline $\begin{array}{l}\text { TBAC:1,3- } \\
\text { DMTU }\end{array}$ & $1: 1$ & 303.15 & $(2.05)^{1}$ & & 512 & & [89] \\
\hline TBAC:Tetz & $1: 1$ & 303.15 & $0.126(1.46)^{1}$ & & 87.88 & 9.85 & [88] \\
\hline $\begin{array}{c}\mathrm{P}_{4444} \mathrm{Br}: 1,3- \\
\text { DMTU }\end{array}$ & $1: 1$ & 303.15 & $(1.13)^{1}$ & & 245 & & [87] \\
\hline $\mathrm{P}_{4444} \mathrm{Br}: \mathrm{DMU}$ & $1: 1$ & 303.15 & $(0.66)^{1}$ & & & & [86] \\
\hline $\mathrm{P}_{4444} \mathrm{Br}: \mathrm{DMU}$ & $1: 2$ & 303.15 & $(0.92)^{1}$ & & & & [86] \\
\hline $\mathrm{P}_{4444} \mathrm{Br}: \mathrm{DMU}$ & $1: 3$ & 303.15 & $(1.17)^{1}$ & & & & [87] \\
\hline $\mathrm{P}_{4444}$ Br:Tetz & $1: 1$ & 303.15 & $0.035(0.48)^{1}$ & & 68.26 & 5.63 & [88] \\
\hline $\begin{array}{c}\mathrm{P}_{4444} \mathrm{Cl}: 1,3- \\
\text { DMTU }\end{array}$ & $1: 3$ & 303.15 & $(4.25)^{1}$ & & 286 & & [87] \\
\hline $\begin{array}{c}\mathrm{P}_{4444} \mathrm{Cl}: 1,3- \\
\text { DMTU }\end{array}$ & $1: 2$ & 303.15 & $(3.18)^{1}$ & & 173 & & [87] \\
\hline $\begin{array}{c}\mathrm{P}_{4444} \mathrm{Cl}: 1,3- \\
\text { DMTU }\end{array}$ & $1: 1$ & 303.15 & $(2.13)^{1}$ & & 105 & & [87] \\
\hline $\mathrm{P}_{4444} \mathrm{Cl}:$ Imid & $1: 1$ & 303.15 & $0.013(0.16)^{1}$ & & 52.34 & 5.16 & [88] \\
\hline $\mathrm{P}_{4444} \mathrm{Cl}:$ Tetz & $1: 1$ & 303.15 & $\begin{array}{c}0.173(2.100) \\
1_{;}(0.231)^{2}\end{array}$ & & 40.22 & 3.15 & [88] \\
\hline $\mathrm{P}_{4444} \mathrm{Cl}$ :Triz & $1: 1$ & 303.15 & $0.059(0.71)^{1}$ & & 67.23 & 7.13 & [88] \\
\hline
\end{tabular}

${ }^{1}$ Data in brackets are the molar fraction. ${ }^{2}$ At $1 \mathrm{kPa}$.

\section{Regeneration}

The regeneration of absorbents is an important property that determines the production cost and the sustainability of equipment investment in industrial processes. Experimentally, the regeneration of an absorbent was conducted by bubbling $\mathrm{N}_{2}$ at a high flow rate into the saturated absorbent to sweep out the absorbed gas or reducing the pressure of absorbents at a desired temperature until the weight of the absorbent maintains constant. The whole process of absorption and desorption is repeated at least five times to verify the reusability of DESs.

The strength of the interaction between an acidic gas and a DES determines the conditions required for desorption. Weak interaction between the gas and the non-functionalized DES makes the desorption process easy and fast. For example, $\mathrm{SO}_{2}$ absorbed by $\mathrm{ChCl}$ :Gly 
DES (1:1) could be completely released by bubbling $\mathrm{N}_{2}$ at $60 \mathrm{~mL} \mathrm{~min}^{-1}$ and $323.15 \mathrm{~K}$ within $20 \mathrm{~min}$ [36]. For other non-functionalized DESs with $\mathrm{ChCl}$ as an $\mathrm{HBA}$, such as $\mathrm{ChCl}: \mathrm{EG}$ (1:2), ChCl:MA (1:1), ChCl:UE (1:2), and ChCl:thiourea (1:1), absorbed $\mathrm{SO}_{2}$ could be completely released at $250 \mathrm{~mL} \mathrm{~min}^{-1}$ and $353.15 \mathrm{~K}$ with $20 \mathrm{~min}$ [39]. Yang et al. [41] reported that the molar ratio of HBA to HBD could also affect the desorption behavior. About 96\% $\mathrm{SO}_{2}$ captured by EmimCl:EG DES (2:1) can be released at $353.15 \mathrm{~K}$ within $50 \mathrm{~min}$. For EmimCl:EG DES (1:1), captured $\mathrm{SO}_{2}$ can be released completely at the same condition. While all $\mathrm{SO}_{2}$ captured by EmimCl:EG DES (1:2) can be desorbed at $333.15 \mathrm{~K}$ within $50 \mathrm{~min}$. The different desorption behaviors are mainly because the increase in EmimCl/EG molar ratio can reduce the interaction between EmimCl and $\mathrm{SO}_{2}$, which is favorable for the desorption process. Compared with functionalized DESs, non-functionalized DESs have a weaker interaction with acidic gases. Thus, it can achieve a higher desorption rate (90 100\%) at lower temperatures (323.15 353.15 K).

For functionalized DESs, the stronger interaction between DESs and gases would make regeneration harder. For instance, due to the strong interaction between NO and DESs, the desorption rates of NO in Tetz: $\mathrm{P}_{4444} \mathrm{Cl}$ DES (1:1) [89], $\mathrm{P}_{4444} \mathrm{Cl}: 1,3-\mathrm{DMTU}$ DES (1:3) [87], [TEPA]Cl:EG DES(1:3) [89] are 66\%, 70\% and 70\%, respectively, at $353.15 \mathrm{~K}$ for $60 \mathrm{~min}$. The desorption rates of $\mathrm{SO}_{2}$ (2 vol \%) in L-car:EG DES (1:3) [57] and Im:Gly DES (1:2) are about $70 \%$ and $80 \%$ at $363.15 \mathrm{~K}$ and $373.15 \mathrm{~K}$, respectively. As the partial pressure of an acidic gas increases, the saturated absorption capacity increases, which leads to an increase in the desorption rate. The desorption rate of EU:4- $\mathrm{CH}_{3}-\mathrm{Im}: \mathrm{BmimCl}(1: 2: 1)$ and EU:4- $\mathrm{CH}_{3}-\mathrm{Im}: \mathrm{BmimCl}$ (1:1:1) for 0.2 vol \% SO 2 could reach $74.6 \%$ and $72.1 \%$, respectively, at $100 \mathrm{~mL} / \mathrm{min}$ and $353.15 \mathrm{~K}$, while the desorption rates were calculated to be $92.1 \%$ and $92.7 \%$, respectively, based on the saturated absorption capacity of pure $\mathrm{SO}_{2}$ at the same conditions [53]. Deng et al. [49] reported that the different desorption behaviors of ACC:Im DES (1:2) and ACC:Tri DES (1:1) were related to the basicity of DESs. For ACC:Tri DES (1:1), absorbed $\mathrm{SO}_{2}$ could be completely stripped out by bubbling $\mathrm{N}_{2}$ at $363.15 \mathrm{~K}$. However, approximately $6 \% \mathrm{SO}_{2}$ still remained after regeneration in ACC:Im DES (1:2) at the same condition. The residue of desorption was attributed to different basicity of DES. It is well-known that the $\mathrm{p} K_{\mathrm{a}}$ values of Im and Tri are 18.6 and 14.8 , respectively. Thus, the basicity of the former is stronger than that of the latter. The interaction between ACC:Im DES (1:2) and $\mathrm{SO}_{2}$ is stronger than that between ACC:Tri DES (1:1) and $\mathrm{SO}_{2}$, which make the desorption harder.

\section{Conclusions and Outlook}

In summary, DESs can effectively absorb $\mathrm{SO}_{2}, \mathrm{CO}_{2}$ and $\mathrm{NO}$ of low concentrations in flue gas, and generally have lower viscosity before absorption compared to ILs. Especially for DESs used for $\mathrm{SO}_{2}$ capture, the absorption capacity of non-functionalized DESs with BmimCl as HBA can be comparable to that of functionalized DESs at low pressures $(\leq 10 \mathrm{kPa})$, but the DESs with $\mathrm{BmimCl}$ as $\mathrm{HBA}$ shows fast desorption rate, low desorption temperature and no desorption residual problem. The synthesis process of DESs is simple and does not require further purification. The absorption capacity and viscosity can be adjusted by changing the molar ratio of $\mathrm{HBD}$ to $\mathrm{HBA}$, which makes a great room for cost adjustment. However, the study on the capture of acidic gases from flue gas by DESs still has a lot of challenges in the near future. First, although DESs used for the absorption of $\mathrm{SO}_{2}$ and $\mathrm{NO}$ can inhibit the significant increase in the viscosity during the absorption process by introducing halogen anions, the significant increase in viscosity caused by the chemical interaction between $\mathrm{CO}_{2}$ and DESs is still remains a challenge. This may limit the application of functionalized DESs in industrial scale. Second, the density, viscosity, solubility enthalpy, heat capacity, toxicity and the long-time stability ( $>6$ months) are important for applications, but they are seldom reported in the literature. Third, because of the limitation of the difficult complete desorption of functionalized DESs, except for changing the type of HBD or HBA, there is no effective method to remove residual gas. The interaction mechanism between residual gas and DESs remains to be studied. Fourth, the molar ratio of HBA to HBD is a 
very important factor for DESs. In general, HBA and HBD can form a DES at molar ratios from 1:1 to 1:7, and the absorption capacity and viscosity can be tuned by changing the molar ratio. Generally, for DESs with chloride salt as an HBA paired with different types of HBDs, the highest mass absorption occurs between the molar ratios of 1:3 to 1:5 (HBD:HBA). However, considering the cost and absorptive capacity, the optimal molar ratio is usually different from that at the highest mass absorption. The influence of molar ratio on absorptive capacity has been widely discussed in previous reports, but it is too dispersed to be studied systematically and lacks in-depth studies. More importantly, the flue gas is made of a variety of gases, and hence it is necessary to study the effects of mixed gases on absorption and regeneration performance. DESs containing polyamine, imidazole and triazole can absorb $\mathrm{SO}_{2}, \mathrm{CO}_{2}$ and $\mathrm{NO}$ simultaneously by the free amino groups in DESs with similar mechanism. The competitive absorption between acidic gases and the competitive desorption of the acidic gases are inevitable problems in industrial applications, but no research in this area has been published. Although there are above challenges, functionalized DESs, especially functionalized DESs with strong physical absorption, show enormous potentials for gases capture with easy preparation, low cost, biodegradability, and nontoxicity.

Author Contributions: Conceptualization, W.W. and Y.W.; writing-original draft preparation, Y.W.; writing - review and editing, W.W., S.R., Y.H.; supervision, W.W. All authors have read and agreed to the published version of the manuscript.

Funding: This research received no external funding.

Institutional Review Board Statement: Not applicable.

Informed Consent Statement: Not applicable.

Data Availability Statement: Not applicable.

Acknowledgments: The long-term subsidy mechanism from the Ministry of Finance and the Ministry of Education of PRC (BUCT) is acknowledged.

Conflicts of Interest: The authors declare no conflict of interest.

\section{Abbreviations}

$\begin{array}{ll}\text { A } & \\ \text { AA } & \text { acetamide } \\ \text { AC } & \text { acetic acid } \\ \text { ACC } & \text { acetyl choline chloride } \\ \text { AIMD } & \text { ab initio molecular dynamics } \\ \text { AP } & \text { 3-amino-1-propanol } \\ \text { AMP } & \text { aminomethoxypropanol } \\ \text { B } & \\ \text { Ben-Im } & \text { benzimidazole } \\ \text { BmimCl } & \text { 1-Butyl-3-methylimidazolium chloride } \\ \text { BmimBr } & \text { 1-Butyl-3-methylimidazolium bromide } \\ \text { [BTPP] } & \text { butyltriphenylphosphonium } \\ \text { BHDE } & \text { N-Benzyl-2-hydroxy- } N \text {, } N \text {-dimethyl ethanaminium chloride } \\ \text { BTEA } & \text { benzyltriethylammonium chloride } \\ \text { BTMA } & \text { benzyltrimethylammonium chloride } \\ \text { C } & \end{array}$




\begin{tabular}{|c|c|}
\hline $\mathrm{ChCl}$ & choline chloride \\
\hline ChAC & choline acetyl chloride \\
\hline $4 \mathrm{CH}_{3}-\mathrm{Im}$ & 4-methylimidazole \\
\hline CPL & caprolactam \\
\hline \multicolumn{2}{|l|}{$\mathrm{D}$} \\
\hline DBN & 1,5-diazabicyclo[4.3.0]-non-5-ene \\
\hline DBU & 1,8-diazabicyclo[5.4.0]undec-7-ene \\
\hline DEA & diethanolamine \\
\hline DecA & decanoic acid \\
\hline DES & deep eutectic solvent \\
\hline DETA & diethylenetriamine \\
\hline DFT & density functional theory \\
\hline DG & diethylene glycol \\
\hline DMU & 1,3-dimethylurea \\
\hline DMLU & dimethylolurea \\
\hline 1,3-DMTU & 1,3-dimethylthiourea \\
\hline DPA & dipropylamine \\
\hline \multicolumn{2}{|r|}{ 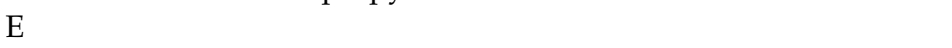 } \\
\hline EDA & ethylendiamine \\
\hline EG & ethylene glycol \\
\hline 2-Et & 2-ethylimidazole \\
\hline EmimCl & 1-ethyl-3-methylimidazolium chloride \\
\hline$[$ Emim $][2-C N p y r]$ & 1-ethyl-3-methylimidazolium 2-cyanopyrrolide \\
\hline EU & ethylenurea \\
\hline \multicolumn{2}{|r|}{ J } \\
\hline Gly & glycerol \\
\hline Gua & guanidinium hydrochloride \\
\hline \multicolumn{2}{|r|}{0} \\
\hline HBAs & hydrogen bond acceptors \\
\hline HBDs & hydrogen bond donors \\
\hline $\mathrm{HmimCl}$ & 1-hexyl-3-methylimidazolium chloride \\
\hline HPLC & high-performance liquid chromatography \\
\hline \multicolumn{2}{|r|}{ Q } \\
\hline ILs & ionic liquids \\
\hline $\operatorname{Im}$ & imidazole \\
\hline \multicolumn{2}{|l|}{$\mathrm{L}$} \\
\hline LA & lactic acid \\
\hline LV & levulinic acid \\
\hline \multicolumn{2}{|l|}{ M } \\
\hline MA & malonic acid \\
\hline MDEA & methyl diethanolamine \\
\hline MEA & monoethanolamine \\
\hline MEAC & monoethanolamine hydrochloride \\
\hline 2-Me & 2-methylimidazole \\
\hline MTBD & 7-methyl-1,5,7-triazabicyclo[4.4.0]dec-5-ene \\
\hline MTPP & methyltriphenyl phosphonium bromide \\
\hline MU & N-methylurea \\
\hline MU & N-methylurea \\
\hline \multicolumn{2}{|r|}{ 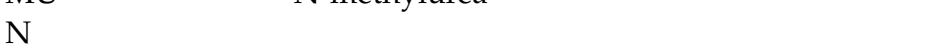 } \\
\hline$\left[\mathrm{N}_{2222}\right][\mathrm{Im}]$ & Tetraethylammonium imidazolium \\
\hline$\left[\mathrm{N}_{2222}\right][$ Triz $]$ & tetraethylammonium \\
\hline$\left[\mathrm{N}_{8881}\right] \mathrm{Cl}$ & methyl trioctyl ammonium chloride \\
\hline$\left[\mathrm{N}_{8888}\right] \mathrm{Br}$ & tetraoctylammonium bromide \\
\hline$\left[\mathrm{N}_{8888}\right] \mathrm{Cl}$ & tetraoctylammonium chloride \\
\hline NFM & N-Formylmorpholine \\
\hline \multicolumn{2}{|r|}{ क्ष } \\
\hline OCT & octanoic acid \\
\hline
\end{tabular}




$\begin{array}{ll}\mathrm{P} & \\ {\left[\mathrm{P}_{2222}\right][\mathrm{Im}]} & \text { tetraethylammonium imidazolium } \\ {\left[\mathrm{P}_{2222}\right][\text { Triz }]} & \text { tetraethylammonium 1,2,4-triazolium } \\ \mathrm{P}_{4444} \mathrm{Cl} & \text { tetrabutylphosphonium chloride } \\ \mathrm{P}_{4444} \mathrm{Br} & \text { tetrabutylphosphonium bromide } \\ \text { 1,3-PDO } & \text { 1,3-propanediol } \\ \text { PEHA } & \text { pentaethylenehexamine } \\ \text { PEG } & \text { polyethylene glycol } \\ \text { PILs } & \text { protic ionic liquids } \\ \text { 2-Pr } & \text { 2-propylimidazole } \\ \text { PPZBr } & \text { 1-hydroxyethyl-1,4-dimethyl-piperazinium bromide } \\ \text { Pyr } & \text { pyrazole } \\ \mathrm{S} & \\ \text { TAC } & \text { thioacetamide } \\ \text { SBs } & \text { Superbases } \\ \text { SN } & \text { succinonitrile } \\ \text { T } & \\ \text { TAA } & \text { thioacetamide } \\ \text { TAAC } & \text { thioacetamide hydrochloride } \\ \text { TBAB } & \text { tetrabutylammonium bromide } \\ \text { TBAC } & \text { tetrabutylammonium chloride } \\ \text { TEA } & \text { triethanolamine } \\ \text { TEAB } & \text { tetraethylammonium bromide } \\ \text { TEAC } & \text { triethanolamine hydrochloride } \\ \text { TEAC } & \text { tetraethylammonium chloride } \\ \text { TEG } & \text { triethylene glycol } \\ \text { TEMA } & \text { triethylmethylammonium chloride } \\ \text { TEPA } & \text { tetra-ethylenepentamine } \\ \text { [TEPA }] C l & \text { tetraethylenepentamine chloride } \\ \text { TETA } & \text { triethylenetetramine } \\ {[\text { TETA }] C l} & \text { triethylenetetramine chloride } \\ \text { Tetz } & \text { tetrazole } \\ \text { TMAC } & \text { tetramethylammonium chloride } \\ \text { TPAC } & \text { tetrapropylammonium chloride } \\ \text { Tri } & \text { 1,2,4-triazole } \\ \text { U } & \\ \text { UE } & \text { urea } \\ \text { UEC } & \text { urea hydrochloride } \\ & \end{array}$

\section{References}

1. Tailor, R.; Abboud, M.; Sayari, A. Supported polytertiary amines: Highly efficient and selective $\mathrm{SO}_{2}$ adsorbents. Environ. Sci. Technol. 2014, 48, 2025-2034. [CrossRef] [PubMed]

2. Thitakamol, B.; Veawab, A.; Aroonwilas, A. Environmental impacts of absorption-based $\mathrm{CO}_{2}$ capture unit for post-combustion treatment of flue gas from coal-fired power plant. Int. J. Greenh. Gas Con. 2007, 1, 318-342. [CrossRef]

3. Fu, S.-L.; Song, Q.; Yao, Q. Mechanism study on the adsorption and reactions of $\mathrm{NH}_{3}, \mathrm{NO}$, and $\mathrm{O}_{2}$ on the $\mathrm{CaO}$ surface in the SNCR deNOx process. Chem. Eng. J. 2016, 285, 137-143. [CrossRef]

4. Shelef, M. Selective catalytic reduction of $\mathrm{NO}_{x}$ with N-Free reductants. Chem. Rev. 1995, 95, 209-225. [CrossRef]

5. Aghaie, M.; Rezaei, N.; Zendehboudi, S. A systematic review on $\mathrm{CO}_{2}$ capture with ionic liquids: Current status and future prospects. Renew. Sust. Energ. Rev. 2018, 96, 502-525. [CrossRef]

6. Chen, K.; Shi, G.; Zhou, X.; Li, H.; Wang, C. Highly efficient nitric oxide capture by azole-based ionic liquids through multiple-site absorption. Angew. Chem. Int. Ed. Engl. 2016, 55, 14364-14368. [CrossRef]

7. Wang, L.; Zhang, Y.; Liu, Y.; Xie, H.; Xu, Y.; Wei, J. SO 2 absorption in pure ionic liquids: Solubility and functionalization. J. Hazard. Mater. 2020, 392, 122504. [CrossRef]

8. Cui, G.; Huang, Y.; Zhang, R.; Zhang, F.; Wang, J. Highly efficient and reversible $\mathrm{SO}_{2}$ capture by halogenated carboxylate ionic liquids. RSC Adv. 2015, 5, 60975-60982. [CrossRef]

9. Cui, G.; Zheng, J.; Luo, X.; Lin, W.; Ding, F.; Li, H.; Wang, C. Tuning anion-functionalized ionic liquids for improved $\mathrm{SO}_{2} \mathrm{capture.}$ Angew. Chem. Int. Ed. Engl. 2013, 52, 10620-10624. [CrossRef] [PubMed] 
10. Lee, K.-Y.; Kim, C.-S.; Kim, H.-G.; Cheong, M.-S.; Mukherjee, D.K.; Jung, K.-D. Effects of halide anions to absorb $\mathrm{SO}_{2}$ in ionic liquids. Bull. Korean Chem. Soc. 2010, 31, 1937-1940. [CrossRef]

11. Wang, J.; Zeng, S.J.; Bai, L.; Gao, H.S.; Zhang, X.P.; Zhang, S.J. Novel ether-functionalized pyridinium chloride ionic liquids for efficient $\mathrm{SO}_{2}$ capture. Ind. Eng. Chem. Res. 2014, 53, 16832-16839. [CrossRef]

12. Cui, G.K.; Lin, W.J.; Ding, F.; Luo, X.Y.; He, X.; Li, H.R.; Wang, C.M. Highly efficient $\mathrm{SO}_{2}$ capture by phenyl-containing azole-based ionic liquids through multiple-site interactions. Green Chem. 2014, 16, 1211-1216. [CrossRef]

13. Cui, G.; Wang, J.; Zhang, S. Active chemisorption sites in functionalized ionic liquids for carbon capture. Chem. Soc. Rev. 2016, 45, 4307-4339. [CrossRef] [PubMed]

14. Cui, G.K.; Zhang, F.T.; Zhou, X.Y.; Huang, Y.J.; Xuan, X.P.; Wang, J.J. Acylamido-based anion-functionalized ionic liquids for efficient $\mathrm{SO}_{2}$ capture through multiple-site interactions. ACS Sustain. Chem. Eng. 2015, 3, 2264-2270. [CrossRef]

15. Cui, G.; Zhang, F.; Zhou, X.; Li, H.; Wang, J.; Wang, C. Tuning the basicity of cyano-containing ionic liquids to improve $\mathrm{SO}_{2}$ capture through cyano-sulfur interactions. Chem. Asian J. 2015, 21, 5632-5639.

16. Cui, G.; Zhao, N.; Wang, J.; Wang, C. Computer-assisted design of imidazolate-based ionic liquids for improving sulfur dioxide capture, carbon dioxide capture, and sulfur dioxide/carbon dioxide selectivity. Chem. Asian J. 2017, 12, 2863-2872. [CrossRef]

17. Huang, K.; Zhang, X.M.; Li, Y.X.; Wu, Y.T.; Hu, X.B. Facilitated separation of $\mathrm{CO}_{2}$ and $\mathrm{SO}_{2}$ through supported liquid membranes using carboxylate-based ionic liquids. J. Membr. Sci. 2014, 471, 227-236. [CrossRef]

18. Ren, S.H.; Hou, Y.C.; Zhang, K.; Wu, W.Z. Ionic liquids: Functionalization and absorption of $\mathrm{SO}_{2}$. Green Energy Environ. 2018, 3 , 179-190. [CrossRef]

19. Zhang, X.; Zhang, X.; Dong, H.; Zhao, Z.; Zhang, S.; Huang, Y. Carbon capture with ionic liquids: Overview and progress. Energy Environ. Sci. 2012, 5, 6668-6681. [CrossRef]

20. Yu, D.; Mou, H.; Fu, H.; Lan, X.; Wang, Y.; Mu, T. "Inverted” deep eutectic solvents based on host-guest interactions. Chem. Asian J. 2019, 14, 4183-4188. [CrossRef]

21. Yu, D.; Mou, H.; Zhao, X.; Wang, Y.; Mu, T. Eutectic molecular liquids based on hydrogen bonding and pi-pi interaction for exfoliating two-dimensional materials and recycling polymers. Chem. Asian J. 2019, 14, 3350-3356. [CrossRef]

22. Yu, D.; Mu, T. Strategy to form eutectic molecular liquids based on noncovalent interactions. J. Phys. Chem. B 2019, 123, 4958-4966. [CrossRef] [PubMed]

23. Abbott, A.P.; Boothby, D.; Capper, G.; Davies, D.L.; Rasheed, R.K. Deep eutectic solvents formed between choline chloride and carboxylic acids: Versatile alternatives to ionic liquids. J. Am. Chem. Soc. 2004, 126, 9142-9147. [CrossRef] [PubMed]

24. Zhu, A.L.; Jiang, T.; Han, B.X.; Zhang, J.C.; Xie, Y.; Ma, X.M. Supported choline chloride/urea as a heterogeneous catalyst for chemical fixation of carbon dioxide to cyclic carbonates. Green Chem. 2007, 9, 169-172. [CrossRef]

25. Hansen, B.B.; Spittle, S.; Chen, B.; Poe, D.; Zhang, Y.; Klein, J.M.; Horton, A.; Adhikari, L.; Zelovich, T.; Doherty, B.W.; et al. Deep eutectic solvents: A review of fundamentals and applications. Chem. Rev. 2021, 121, 1232-1285. [CrossRef]

26. Liu, Y.; Dai, Z.; Zhang, Z.; Zeng, S.; Li, F.; Zhang, X.; Nie, Y.; Zhang, L.; Zhang, S.; Ji, X. Ionic liquids/deep eutectic solvents for $\mathrm{CO}_{2}$ capture: Reviewing and evaluating. Green Energy Environ. 2020. [CrossRef]

27. Hou, Y.C.; Yao, C.F.; Wu, W.Z. Deep eutectic solvents: Green solvents for separation applications. Acta Phys. Chim. Sin. 2018, 34, 873-885. [CrossRef]

28. Chen, Y.; Han, X.X.; Liu, Z.H.; Yu, D.K.; Guo, W.G.; Mu, T.C. Capture of toxic gases by deep eutectic solvents. ACS Sustain. Chem. Eng. 2020, 8, 5410-5430. [CrossRef]

29. Guo, B.; Duan, E.; Ren, A.; Wang, Y.; Liu, H. Solubility of $\mathrm{SO}_{2}$ in caprolactam tetrabutyl ammonium bromide ionic liquids. J. Chem. Eng. Data 2010, 55, 1398-1401. [CrossRef]

30. Liu, B.Y.; Zhao, J.J.; Wei, F.X. Characterization of caprolactam based eutectic ionic liquids and their application in $\mathrm{SO}_{2}$ absorption. J. Mol. Liq. 2013, 180, 19-25. [CrossRef]

31. Liu, B.Y.; Wei, F.X.; Zhao, J.J.; Wang, Y.Y. Characterization of amide-thiocyanates eutectic ionic liquids and their application in $\mathrm{SO}_{2}$ absorption. RSC Adv. 2013, 3, 2470-2476. [CrossRef]

32. Ding, F.; Zheng, J.J.; Chen, Y.Q.; Chen, K.H.; Cui, G.K.; Li, H.R.; Wang, C.M. Highly efficient and reversible $\mathrm{SO}_{2}$ capture by surfactant-derived dual functionalized ionic liquids with metal chelate cations. Ind. Eng. Chem. Res. 2014, 53, 18568-18574. [CrossRef]

33. Wang, C.; Zheng, J.; Cui, G.; Luo, X.; Guo, Y.; Li, H. Highly efficient $\mathrm{SO}_{2}$ capture through tuning the interaction between anion-functionalized ionic liquids and $\mathrm{SO}_{2}$. Chem. Commun. 2013, 49, 1166-1168. [CrossRef] [PubMed]

34. Ghobadi, A.F.; Taghikhani, V.; Elliott, J.R. Investigation on the solubility of $\mathrm{SO}_{2}$ and $\mathrm{CO}_{2}$ in imidazolium-based ionic liquids using NPT Monte Carlo simulation. J. Phys. Chem. B 2011, 115, 13599-13607. [CrossRef] [PubMed]

35. Mondal, A.; Balasubramanian, S. Understanding $\mathrm{SO}_{2}$ capture by ionic liquids. J. Phys. Chem. B 2016, 120, 4457-4466. [CrossRef] [PubMed]

36. Yang, D.Z.; Hou, M.Q.; Ning, H.; Zhang, J.L.; Ma, J.; Yang, G.Y.; Han, B.X. Efficient $\mathrm{SO}_{2}$ absorption by renewable choline chloride-glycerol deep eutectic solvents. Green Chem. 2013, 15, 2261-2265. [CrossRef]

37. Korotkevich, A.; Firaha, D.S.; Padua, A.A.H.; Kirchner, B. Ab initio molecular dynamics simulations of $\mathrm{SO}_{2}$ solvation in choline chloride/glycerol deep eutectic solvent. Fluid Phase Equilib. 2017, 448, 59-68. [CrossRef] 
38. Li, H.P.; Chang, Y.H.; Zhu, W.S.; Wang, C.W.; Wang, C.; Yin, S.; Zhang, M.; Li, H.M. Theoretical evidence of charge transfer interaction between $\mathrm{SO}_{2}$ and deep eutectic solvents formed by choline chloride and glycerol. Phys. Chem. Chem. Phys. 2015, 17, 28729-28742. [CrossRef]

39. Sun, S.Y.; Niu, Y.X.; Xu, Q.; Sun, Z.C.; Wei, X.H. Efficient $\mathrm{SO}_{2}$ absorptions by four kinds of deep eutectic solvents based on choline chloride. Ind. Eng. Chem. Res. 2015, 54, 8019-8024. [CrossRef]

40. Deng, D.; Han, G.; Jiang, Y. Investigation of a deep eutectic solvent formed by levulinic acid with quaternary ammonium salt as an efficient $\mathrm{SO}_{2}$ absorbent. New J. Chem. 2015, 39, 8158-8164. [CrossRef]

41. Yang, D.Z.; Han, Y.L.; Qi, H.B.; Wang, Y.B.; Dai, S. Efficient absorption of $\mathrm{SO}_{2}$ by EmimCl-EG deep eutectic solvents. ACS Sustain. Chem. Eng. 2017, 5, 6382-6386. [CrossRef]

42. Yang, D.; Zhang, S.; Jiang, D.E.; Dai, S. $\mathrm{SO}_{2}$ absorption in EmimCl-TEG deep eutectic solvents. Phys. Chem. Chem. Phys. 2018, 20, 15168-15173. [CrossRef] [PubMed]

43. Yang, D.; Zhang, S.; Jiang, D.-E. Efficient absorption of $\mathrm{SO}_{2}$ by deep eutectic solvents formed by biobased aprotic organic compound succinonitrile and 1-Ethyl-3-methylimidazolium chloride. ACS Sustain. Chem. Eng. 2019, 7, 9086-9091. [CrossRef]

44. Jiang, B.; Zhang, H.M.; Zhang, L.H.; Zhang, N.; Huang, Z.H.; Chen, Y.; Sun, Y.L.; Tantai, X.W. Novel deep eutectic solvents for highly efficient and reversible absorption of $\mathrm{SO}_{2}$ by preorganization strategy. ACS Sustain. Chem. Eng. 2019, 7, 8347-8357. [CrossRef]

45. Zhao, T.X.; Liang, J.; Zhang, Y.T.; Wu, Y.T.; Hu, X.B. Unexpectedly efficient $\mathrm{SO}_{2}$ capture and conversion to sulfur in novel imidazole-based deep eutectic solvents. Chem. Commun. 2018, 54, 8964-8967. [CrossRef] [PubMed]

46. Deng, D.S.; Zhang, C.; Deng, X.X.; Gong, L. Efficient Absorption of low partial pressure $\mathrm{SO}_{2}$ by 1-Ethyl-3-methylimidazolium chloride plus N-Formylmorpholine deep eutectic solvents. Energy Fuels 2019, 34, 665-671. [CrossRef]

47. Yang, X.Q.; Zhang, Y.T.; Liu, F.; Chen, P.; Zhao, T.X.; Wu, Y.T. Deep eutectic solvents consisting of EmimCl and amides: Highly efficient $\mathrm{SO}_{2}$ absorption and conversion. Sep. Purif. Technol. 2020, 250, 117273. [CrossRef]

48. Sheng, K.; Kang, Y.; Li, J.; Xu, H.Y.; Li, D. High-efficiency absorption of $\mathrm{SO}_{2}$ by a new type of deep eutectic solvents. Energy Fuels 2020, 34, 3440-3448. [CrossRef]

49. Deng, D.S.; Liu, X.B.; Gao, B. Physicochemical properties and investigation of azole-based deep eutectic solvents as efficient and reversible $\mathrm{SO}_{2}$ absorbents. Ind. Eng. Chem. Res. 2017, 56, 13850-13856. [CrossRef]

50. Zhang, K.; Ren, S.H.; Yang, X.; Hou, Y.C.; Wu, W.Z.; Bao, Y.Y. Efficient absorption of low-concentration $\mathrm{SO}_{2}$ in simulated flue gas by functional deep eutectic solvents based on imidazole and its derivatives. Chem. Eng. J. 2017, 327, 128-134. [CrossRef]

51. Gao, M.J.; Hou, Y.C.; Zhang, Q.; Sun, Y.; Ren, S.H.; Wu, W.Z. Absorption of $\mathrm{SO}_{2}$ in simulated flue gas by functional deep eutectic solvents based on imidazole and $\mathrm{H}_{2} \mathrm{O}$ with high mass capacities. Energy Fuels 2020, 34, 4754-4760. [CrossRef]

52. Chen, Y.; Jiang, B.; Dou, H.Z.; Zhang, L.H.; Tantai, X.W.; Sun, Y.L.; Zhang, H.M. Highly efficient and reversible capture of low partial pressure $\mathrm{SO}_{2}$ by functional deep eutectic solvents. Energy Fuels 2018, 32, 10737-10744. [CrossRef]

53. Hou, S.; Zhang, C.C.; Jiang, B.; Zhang, H.M.; Zhang, L.H.; Yang, N.; Zhang, N.; Xiao, X.M.; Tantai, X.W. Investigation of highly efficient and reversible absorption of $\mathrm{SO}_{2}$ using ternary functional deep eutectic solvents. ACS Sustain. Chem. Eng. 2020, 8 , 16241-16251. [CrossRef]

54. Cui, G.K.; Liu, J.X.; Lyu, S.Z.; Wang, H.Y.; Li, Z.Y.; Wang, J.J. Efficient and reversible $\mathrm{SO}_{2}$ absorption by environmentally friendly task-specific deep eutectic solvents of PPZBr + Gly. ACS Sustain. Chem. Eng. 2019, 7, 14236-14246. [CrossRef]

55. Ren, S.H.; Hou, Y.C.; Wu, W.Z.; Liu, Q.Y.; Xiao, Y.F.; Chen, X.T. Properties of ionic liquids absorbing $\mathrm{SO}_{2}$ and the mechanism of the absorption. J. Phys. Chem. B 2010, 114, 2175-2179. [CrossRef]

56. Zeng, S.J.; Zhang, X.C.; Gao, H.S.; He, H.Y.; Zhang, X.P.; Zhang, S.J. $\mathrm{SO}_{2}$-induced variations in the viscosity of ionic liquids investigated by in situ fourier transform infrared spectroscopy and simulation calculations. Ind. Eng. Chem. Res. 2015, 54, 10854-10862. [CrossRef]

57. Zhang, K.; Ren, S.H.; Hou, Y.C.; Wu, W.Z. Efficient absorption of $\mathrm{SO}_{2}$ with low-partial pressures by environmentally benign functional deep eutectic solvents. J. Hazard. Mater. 2017, 324, 457-463. [CrossRef]

58. Leron, R.B.; Li, M.H. Solubility of carbon dioxide in a eutectic mixture of choline chloride and glycerol at moderate pressures. J. Chem. Thermodyn. 2013, 57, 131-136. [CrossRef]

59. Li, X.Y.; Hou, M.Q.; Han, B.X.; Wang, X.L.; Zou, L.Z. Solubility of $\mathrm{CO}_{2}$ in a choline chloride + urea eutectic mixture. J. Chem. Eng. Data 2008, 53, 548-550. [CrossRef]

60. Mirza, N.R.; Nicholas, N.J.; Wu, Y.; Mumford, L.A.; Kentish, S.E.; Stevens, G.W. Experiments and thermodynamic modeling of the solubility of carbon dioxide in three different deep eutectic solvents (DESs). J. Chem. Eng. Data 2015, 60, 3246-3252. [CrossRef]

61. Zhang, Y.Y.; Ji, X.Y.; Lu, X.H. Choline-based deep eutectic solvents for $\mathrm{CO}_{2}$ separation: Review and thermodynamic analysis. Renew. Sust. Energ. Rev. 2018, 97, 436-455. [CrossRef]

62. Ali, E.; Hadj-Kali, M.K.; Mulyono, S.; Alnashef, I.; Fakeeha, A.; Mjalli, F.; Hayyan, A. Solubility of $\mathrm{CO}_{2}$ in deep eutectic solvents: Experiments and modelling using the Peng-Robinson equation of state. Chem. Eng. Res. Des. 2014, 92, 1898-1906. [CrossRef]

63. Sarmad, S.; Xie, Y.J.; Mikkola, J.-P.; Ji, X.Y. Screening of deep eutectic solvents (DESs) as green $\mathrm{CO}_{2}$ sorbents: From solubility to viscosity. New J. Chem. 2017, 41, 290-301. [CrossRef]

64. Zubeir, L.F.; van Osch, D.J.G.P.; Rocha, M.A.A.; Banat, F.; Kroon, M.C. Carbon dioxide solubilities in decanoic acid-based hydrophobic deep eutectic solvents. J. Chem. Eng. Data 2018, 63, 913-919. [CrossRef] 
65. Cao, L.D.; Huang, J.H.; Zhang, X.P.; Zhang, S.J.; Gao, J.B.; Zeng, S.J. Imidazole tailored deep eutectic solvents for $\mathrm{CO}_{2}$ capture enhanced by hydrogen bonds. Phys. Chem. Chem. Phys. 2015, 17, 27306-27316. [CrossRef]

66. Trivedi, T.J.; Lee, J.H.; Lee, H.J.; Jeong, Y.K.; Choi, J.W. Deep eutectic solvents as attractive media for $\mathrm{CO}_{2}$ capture. Green Chem. 2016, 18, 2834-2842. [CrossRef]

67. Shukla, S.K.; Mikkola, J.P. Intermolecular interactions upon carbon dioxide capture in deep-eutectic solvents. Phys. Chem. Chem. Phys. 2018, 20, 24591-24601. [CrossRef] [PubMed]

68. Zhang, K.; Hou, Y.C.; Wang, Y.M.; Wang, K.; Ren, S.H.; Wu, W.Z. Efficient and reversible absorption of $\mathrm{CO}_{2}$ by functional deep eutectic solvents. Energy Fuels 2018, 32, 7727-7733. [CrossRef]

69. Gu, Y.X.; Hou, Y.C.; Ren, S.H.; Sun, Y.; Wu, W.Z. Hydrophobic functional deep eutectic solvents used for efficient and reversible capture of $\mathrm{CO}_{2}$. ACS Omega 2020, 5, 6809-6816. [CrossRef] [PubMed]

70. Li, Z.; Wang, L.L.; Li, C.P.; Cui, Y.N.; Li, S.M.; Yang, G.; Shen, Y.M. Absorption of carbon dioxide using ethanolamine-based deep eutectic solvents. ACS Sustain. Chem. Eng. 2019, 7, 10403-10414. [CrossRef]

71. Cui, G.; Lv, M.; Yang, D. Efficient $\mathrm{CO}_{2}$ absorption by azolide-based deep eutectic solvents. Chem Commun. 2019, 55, 1426-1429. [CrossRef] [PubMed]

72. Gurkan, B.; Goodrich, B.F.; Mindrup, E.M.; Ficke, L.E.; Massel, M.; Seo, S.; Senftle, T.P.; Wu, H.; Glaser, M.F.; Shah, J.K.; et al. Molecular design of high capacity, low viscosity, chemically tunable ionic liquids for $\mathrm{CO}_{2}$ capture. J. Phys. Chem. Lett. 2010, 1, 3494-3499. [CrossRef]

73. Liu, F.; Shen, Y.; Shen, L.; Sun, C.; Chen, L.; Wang, Q.L.; Li, S.J.; Li, W. Novel amino-functionalized ionic liquid/organic solvent with low viscosity for $\mathrm{CO}_{2}$ capture. Environ. Sci. Technol. 2020, 54, 3520-3529. [CrossRef]

74. Lee, Y.Y.; Penley, D.; Klemm, A.; Dean, W.; Gurkan, B. Deep eutectic solvent formed by imidazolium cyanopyrrolide and ethylene glycol for reactive $\mathrm{CO}_{2}$ separations. ACS Sustain. Chem. Eng. 2021, 9, 1090-1098. [CrossRef]

75. Kaljurand, I.; Koppel, I.A.; Kütt, A.; Rõõm, E.-I.; Rodima, T.; Koppel, I.; Mishima, M.; Leito, I. Experimental gas-phase basicity scale of superbasic phosphazenes. J. Phys. Chem. A 2007, 111, 1245-1250. [CrossRef]

76. Luo, H.; Baker, G.A.; Lee, J.S.; Pagni, R.M.; Dai, S. Ultrastable superbase-derived protic ionic liquids. J. Phys. Chem. B 2009, 113, 4181-4183. [CrossRef]

77. Sze, L.L.; Pandey, S.; Ravula, S.; Pandey, S.; Zhao, H.; Baker, G.A.; Baker, S.N. Ternary deep eutectic solvents tasked for carbon dioxide capture. ACS Sustain. Chem. Eng. 2014, 2, 2117-2123. [CrossRef]

78. Jiang, B.; Ma, J.W.; Yang, N.; Huang, Z.H.; Zhang, N.; Tantai, X.W.; Sun, Y.L.; Zhang, L.H. Superbase/acylamido-based deep eutectic solvents for multiple-site efficient $\mathrm{CO}_{2}$ absorption. Energy Fuels 2019, 33, 7569-7577. [CrossRef]

79. Zhang, N.; Huang, Z.H.; Zhang, H.M.; Ma, J.W.; Jiang, B.; Zhang, L.H. Highly efficient and reversible $\mathrm{CO}_{2}$ capture by Task-specific deep eutectic solvents. Ind. Eng. Chem. Res. 2019, 58, 13321-13329. [CrossRef]

80. Yan, H.; Zhao, L.; Bai, Y.G.; Li, F.F.; Dong, H.F.; Wang, H.; Zhang, X.P.; Zeng, S.J. Superbase ionic liquid-based deep eutectic solvents for improving $\mathrm{CO}_{2}$ absorption. ACS Sustain. Chem. Eng. 2020, 8, 2523-2530. [CrossRef]

81. Duan, E.H.; Guo, B.; Zhang, D.D.; Shi, L.; Sun, H.; Wang, Y. Absorption of $\mathrm{NO}$ and $\mathrm{NO}_{2}$ in caprolactam tetrabutyl ammonium halide ionic liquids. J. Air Waste Manag. Assoc. 2011, 61, 1393-1397. [CrossRef]

82. Ando, R.A.; Siqueira, L.; Bazito, F.C.; Torresi, R.M.; Santos, P.S. The sulfur dioxide-1-Butyl-3-Methylimidazolium bromide interaction: Drastic changes in structural and physical properties. J. Phys. Chem. B 2007, 111, 8717-8719. [CrossRef]

83. Laali, K.K.; Geissler, B.; Wagner, O.; Hoffmann, J.; Armbrust, R.; Eisfeld, W.; Regitz, M. Generation of the first persistent phosphirenyiium cation. J. Am. Chem. Soc. 1994, 116, 9407-9408. [CrossRef]

84. Drago, R.S.; Paulik, F.E. The reaction of nitrogen(II) oxide with diethylamine. J. Am. Chem. Soc. 1960, 82, 96-98. [CrossRef]

85. Drago, R.S.; Ragsdale, R.O.; Eyman, D.P. A mechanism for the reaction of diethylamine with nitric oxide. J. Am. Chem. Soc. 1961, 83, 4337-4339. [CrossRef]

86. Jiang, B.; Lin, W.R.; Zhang, L.H.; Sun, Y.L.; Yang, H.W.; Hao, L.; Tantai, X.W. 1,3-Dimethylurea tetrabutylphosphonium bromide ionic liquids for NO efficient and reversible capture. Energy Fuels 2016, 30, 735-739. [CrossRef]

87. Sun, Y.L.; Wei, G.S.; Tantai, X.W.; Huang, Z.H.; Yang, H.W.; Zhang, L.H. Highly efficient nitric oxide absorption by environmentally friendly deep eutectic solvents based on 1,3-Dimethylthiourea. Energy Fuels 2017, 31, 12439-12445. [CrossRef]

88. Zhang, L.H.; Ma, H.P.; Wei, G.S.; Jiang, B.; Sun, Y.L.; Tantai, X.W.; Huang, Z.H.; Chen, Y. Efficient and reversible nitric oxide absorption by low-viscosity, azole-derived deep eutectic solvents. J. Chem. Eng. Data 2019, 64, 3068-3077. [CrossRef]

89. Sun, Y.; Gao, M.J.; Ren, S.H.; Zhang, Q.; Hou, Y.C.; Wu, W.Z. Highly efficient absorption of NO by amine-based functional deep eutectic solvents. Energy Fuels 2019, 34, 690-697. [CrossRef] 